\title{
Efficient toluene adsorption/desorption on biochar derived from in situ acid-treated sugarcane bagasse
}

\author{
Yuan Qu \\ Hubei Polytechnic University
}

Li Xu

Shanwei polutechnic

Yi Chen

Wuhan University of Science and Technology

Shikuan Sun

Foshan University

\section{Yu Wang}

Wuhan University of Science and Technology

\section{Li Min Guo ( $\nabla$ Imguo@hust.edu.cn )}

Huazhong University of Science and Technology - Main Campus: Huazhong University of Science and Technology https://orcid.org/0000-0002-6834-2758

\section{Research Article}

Keywords: hydrochar, VOCs, activated carbons, hydrothermal carbonization, sulfuric acid

Posted Date: April 7th, 2021

DOl: https://doi.org/10.21203/rs.3.rs-354810/v1

License: (c) (1) This work is licensed under a Creative Commons Attribution 4.0 International License. Read Full License

Version of Record: A version of this preprint was published at Environmental Science and Pollution Research on July 1st, 2021. See the published version at https://doi.org/10.1007/s11356-021-15128-2. 


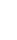
2

\title{
Efficient toluene adsorption/desorption on biochar derived from in situ acid-treated sugarcane bagasse
}

\author{
Yuan $\mathrm{Qu}^{1}, \mathrm{Li} \mathrm{Xu}^{2, *}, \mathrm{Yi} \mathrm{Chen}^{3}$, Shikuan $\mathrm{Sun}^{4}$, Yu Wang ${ }^{3, * *}$ and Limin $\mathrm{Guo}^{5, * * *}$
}

${ }^{1}$ School of Material Science and Engineering, Hubei Polytechnic University, Huangshi 435003, PR China

${ }^{2}$ Department of Ocean Engineering, Shanwei Polytechnic, Shanwei 516600, PR China

${ }^{3}$ College of Resources and Environmental Engineering, Wuhan University of Science and Technology, Wuhan 430081, PR China

${ }^{4}$ School of Material Science and Energy Engineering, Foshan University, Foshan, 528000, PR China

${ }^{5}$ School of Environmental Science and Technology, Huazhong University of Science and Technology, Wuhan, 430074, PR China

* Corresponding author

Email: xuli3021@gmail.com (L. Xu)

** Corresponding author

Email: yuwang@wust.edu.cn (Y. Wang)

*** Corresponding author

Email: 1mguo@ @ust.edu.cn (L. M. Guo) 
Carbon-based materials with great adsorption performance are of importance to meet the

17 needs of industrial gas adsorption. Being massive agricultural wastes of sugarcane bagasse,

18 China could use this waste into wealth. However, the comprehensive utilization of sugarcane bagasse as precursors for biochar that can be used as adsorbent has not been extensively explored. In this study, a series of in-situ sulfuric acid modified biochar were prepared by hydrothermal carbonization process. The prepared biochar (SBAC-7) is combined of two main advantages that are high microporosity (micropore surface area $=1106 \mathrm{~m}^{2} / \mathrm{g}$ ) and rich in Scontaining functional groups on the surface. In particular, SBAC-7 showed an excellent adsorption capacity of toluene $(771.1 \mathrm{mg} / \mathrm{g})$ at $30{ }^{\circ} \mathrm{C}$, which is nearly 3 times as high as the commercial activated carbons. Meanwhile, it showed great stability and cyclic regeneration performance with five toluene adsorption-desorption test cycles. This study provides a highperformance biochar for adsorption-desorption cycle in practical engineering applications, and would contribute to the sustainable "sugarcane production - bagasse utilization" circular economy.

Key words: hydrochar; VOCs; activated carbons; hydrothermal carbonization; sulfuric acid 


\section{Introduction}

Volatile organic compounds (VOCs) are widely used in industries including petrochemicals, printing, pharmaceuticals and painting. VOCs are typical precursors in the atmospheric chemistry, contributing to the production of ozone, secondary organic aerosols, and greenhouse gases (He et al. 2019). In recent decades, various technologies for VOCs removal have been investigated, such as adsorption, membrane separation, catalytic combustion and photocatalytic degradation (Huang et al. 2020b, Li et al. 2020, Shu et al. 2019, Wang et al. 2020c, Wang et al. 2021). Among them, adsorption method has been considered as one of the most practical and effective technologies because of its low cost, easy operation and high treatment effects. Activated carbon (AC) is commonly used as adsorbents of VOCs because of their developed surface area and large pore volumes. However, traditional raw material like coal for AC preparation is non-renewable resources. And the main disadvantages of using these commercial AC materials for the VOCs adsorption are high production costs and secondary pollution during the preparation process.

Biochar derived from hydrothermal carbonization of carbohydrate-rich bio-resources was an ideal material for the purification of polluted water or air (Oliveira et al. 2019). Hydrothermal carbonization process could be directly applied to biomass with high moisture without predrying. Biochar has attracted many attention because of its potential in several crucial fields, such as catalysis, energy storage, $\mathrm{CO}_{2}$ utilization and air purification (Wang et al. 2018a). Among the bio-resources, sugarcane bagasse (SB) with high carbon content, natural fibrous structure and huge amount of production is considered as an ideal precursor (Huang et al. 2020a). Sugarcane is a perennial $\mathrm{C}_{4}$ crop cultivated in subtropical and tropical zones 
worldwide. The high yields of lignocellulosic SB are considered as an excellent source for substituting fossil fuel as precursors. China is ranked in the third position in the world in sugarcane production (Huang et al. 2020a), however, the utilization of SB as precursors of biochar has not been extensively studied.

There is a growing consensus on modulating the functional group and internal textural structure, which play key factors in improving the adsorption performance of carbon-based material. The surface functional group can be modified by using various methods including acid/base treatment, chemical oxidation or impregnation with metal elements (Jin et al. 2020, Tang et al. 2020, Wang et al. 2020a). Notably, acid modification can change the surface alkalinity and oxygen-containing functional groups, which thus enhance the VOC selectivity and adsorption capacity (Kim et al. 2006, Tham et al. 2011, Vega et al. 2013b). Pak et al. reported that the AC treated by 10 vol\% sulfuric acid showed a $47 \%$ increase in toluene adsorption capacity (Pak et al. 2016). Although these methods are effective to increase the oxygen-containing functional groups on the surface of $\mathrm{AC}$, the specific surface area often decreases during the treatment process due to the block of internal textural structure. On the other hand, there are many other methods to modify activated carbon on internal textural structure, such as microwave modification, heat treatment modification, and hot steam treatment modification (Alslaibi et al. 2013). Based on the above studies, it is recognized that functional group and internal textural structure simultaneously. 
evaluate the adsorptive properties of the as-prepared samples by the dynamic breakthrough experiments. The desorption property of in situ acid-treated biochar was also studied. This work is expected to expand the utilization of agricultural waste for air pollutant removal, plus a simple, low-cost, and efficient in-situ modification method.

\section{Experimental}

\subsection{Raw materials}

The original sugarcane bagasse (SB) was purchased form Guangxi Sugarcane Industry Research Institute (China), which was firstly pretreated by washing, drying and crushing into 0.6-0.8 mm. Sulfuric acid $\left(\mathrm{H}_{2} \mathrm{SO}_{4}, 98\right.$ wt.\%), potassium hydroxide (KOH, 85 wt.\%), hydrochloric acid $\left(\mathrm{HCl}, 38\right.$ wt.\%) and toluene $\left(\mathrm{C}_{7} \mathrm{H}_{8}, 99.5\right.$ wt.\%) were provided by Sinopharm Chemical Reagent Co., Ltd.

\subsection{Sample preparation}

Hydrothermal method was used to prepare activated carbon with deionized water or different concentrations of sulfuric acid solution (the concentration of sulfuric acid $=3,5,7,9$ wt.\%). Typically, $3.0 \mathrm{~g}$ of the pretreated SB and $60 \mathrm{~mL}$ of deionized water or sulfuric acid solution were mixed into the reaction kettle and hydrothermal carbonization for $10 \mathrm{~h}$ at $240{ }^{\circ} \mathrm{C}$. After cooling down naturally, the black samples were washed thoroughly with deionized water to neutral and dried at $105{ }^{\circ} \mathrm{C}$ overnight. And the carbonized product was obtained. Then, the carbonized product was impregnated with $\mathrm{KOH}$ solution $(\mathrm{KOH} /$ carbonized product weight ratio was 1.0) for $12 \mathrm{~h}$. After drying at $105^{\circ} \mathrm{C}$ for $12 \mathrm{~h}$, the impregnated samples were activated at $800{ }^{\circ} \mathrm{C}$ for 1 hour under $\mathrm{N}_{2}$ flow, with a heating rate of $10{ }^{\circ} \mathrm{C} / \mathrm{min}$. After cooling down naturally, the samples were washed with $\mathrm{HCl}(10 \mathrm{wt} . \%)$ and deionized water until $\mathrm{pH}=7 \pm$ 
SBAC-x $(x=0,3,5,7,9), x$ means the concentration of sulfuric acid solution.

102

\subsection{Characterization}

The crystalline phase of the samples was determined by X-ray diffraction (XRD, Rigaku/SmartLab SE), which was referred to International Centre for Diffraction Data (ICDD). The morphology was detected by scanning electron microscopy (SEM, ThermoFisher/Apreo S HiVac). The specific surface area, pore volume and pore diameter distribution were measured by $\mathrm{N}_{2}$ adsorption-desorption isotherms at $-196{ }^{\circ} \mathrm{C}$ using Micromeritics Tristar 3020 . The specific surface area was calculated by using BET method according to nitrogen adsorption data in the relative pressure $\left(P / P_{0}\right)$ range of $0.05-0.30$. Sulfur, carbon and oxygen species in the samples were determined by X-ray photoelectron spectroscopy (XPS, AXIS SUPRA+) and Fourier transform infrared (FT-IR) spectra on a Bruker Tensor II spectrometer.

\subsection{Toluene adsorption-desorption test}

The toluene adsorption performance of SBAC-x was carried out by dynamic adsorption experiments at room temperature. The simulated exhaust gas consisted of $1,000 \mathrm{ppm}$ toluene, $20 \% \mathrm{O}_{2}$ and $\mathrm{N}_{2}$ as balance gas. $40 \mathrm{mg}$ sample was weighed and put into a quartz tube, with quartz wool blocked on both sides. Before adsorption experiments, the sample was firstly degassed in $110{ }^{\circ} \mathrm{C}$ under $\mathrm{N}_{2}$ flow to remove those adsorbed impurities. After cooling down to room temperature, the simulated exhaust gas was introduced to flow through the sample at a rate of $100 \mathrm{~mL} / \mathrm{min}$ at a GHSV of $150,000 \mathrm{~mL} /(\mathrm{g} \cdot \mathrm{h})$. The tail gas from the reaction tube was led to the Gas Chromatograph (GC), and the concentration of toluene was noted every four minutes. The adsorption capacity was calculated through the integrals of the breakthrough 
curve by using Eq. (1)

$$
\mathrm{q}_{\mathrm{e}}=\frac{\mathrm{FMC}_{0}}{22.4 * \mathrm{~m}} \int_{0}^{t}\left(1-\frac{C_{t}}{C_{0}}\right) \mathrm{dt}
$$

where $q_{\mathrm{e}}(\mathrm{mg} / \mathrm{g})$ is the calculated adsorption capacity, $F(\mathrm{~mL} / \mathrm{min})$ is the gas flow rate, $\mathrm{M}$ $(\mathrm{g} / \mathrm{mol})$ is the relative molecular mass of adsorbate, $C_{0}(\mathrm{mg} / \mathrm{mL})$ is the initial toluene concentration, $C_{t}(\mathrm{mg} / \mathrm{mL})$ is outlet toluene concentration at time $t(\mathrm{~min}), m(\mathrm{~g})$ is the mass of adsorbent used in the absorption experiment, and $t(\mathrm{~min})$ is the adsorption time.

In toluene desorption experiment, the temperature of the tested samples was elevated from 30 to $450{ }^{\circ} \mathrm{C}$ with a heating rate of $2.5^{\circ} \mathrm{C} / \mathrm{min}$ under $100 \mathrm{~mL} / \mathrm{min} \mathrm{N}_{2}$. The toluene concentration of the effluent gas was measured by GC. Carbon balance $\left(B_{c}\right)$ is calculated based on the peak areas of toluene desorption $\left(q_{\text {toluene }}^{\text {desprion }}\right)$.

$$
B_{\mathrm{c}}(\%)=\frac{q_{\text {toluenen }}^{\text {despion }}}{q_{e}} \times 100 \%
$$

\section{Results and discussion}

\subsection{Textural properties}

XRD was carried out to investigate the crystallinity of SBAC-x as shown in Fig. 1. The as-prepared biochar showed broad peaks, indicating the amorphous structure (Gao et al. 2015). The broad peak in the range of $20-30^{\circ}$ could be assigned to (002) plane of amorphous carbon. And the broad hump in the range of $40-50^{\circ}$ was related to (100) plane, which were caused by diffusion scattering of the amorphous carbon (Chen et al. 2012, Cheng et al. 2020).

$\mathrm{N}_{2}$ sorption isotherms and pore size distributions of the samples were depicted in Fig. 2 and the textural properties were shown in Table 1. According to Fig. 2a, the sorption isotherm of SBAC-0 presented a hysteresis loop when the relative pressure $P / P_{0}>0.4$, which was associated with the capillary condensation of $\mathrm{N}_{2}$. This phenomenon revealed that the untreated 
SBAC-0 was rich in mesoporous channels (Wang et al. 2020b), and the surface area $\left(S_{\mathrm{BET}}\right)$ and total pore volume $\left(V_{\mathrm{t}}\right)$ of SBAC-0 was $1137 \mathrm{~m}^{2} / \mathrm{g}$ and $0.76 \mathrm{~cm}^{3} / \mathrm{g}$, respectively. Notably, after the in situ sulfuric acid treatment, the $S_{\mathrm{BET}}$ and $V_{\mathrm{t}}$ of SBAC-x $(\mathrm{x}=3,5,7,9)$ were significantly enhanced. Specifically, the $S_{\mathrm{BET}}$ of SBAC-3, 5, 7 sharply increased to 2154, 2215 and 2455 $\mathrm{m}^{2} / \mathrm{g}$, while the $V_{\mathrm{t}}$ values increased to $1.24 \sim 1.26 \mathrm{~cm}^{3} / \mathrm{g}$, respectively (Table 1). These results may be attributed to the in-situ interaction between sulfuric acid and the fibers of sugarcane during the hydrothermal carbonization, which could provide more adsorption site for the adsorbate. The fibers of the sugarcane are composed of three major components (cellulose, hemicellulose and lignin), and it was reported that the hemicellulose can be removed by acid through etching effect (Huang et al. 2020a). Thus, both of the micropore surface area (1106 $\left.\mathrm{m}^{2} / \mathrm{g}\right)$ and the mesoporous surface area $\left(1349 \mathrm{~m}^{2} / \mathrm{g}\right)$ enlarged over the SBAC-7 sample than those of SBAC-0 under an appropriate concentration of sulfuric acid. When further increasing the sulfuric acid concentration to 9 wt.\%, however, the micropore surface area of SBAC-9 decreased precipitously to $196 \mathrm{~m}^{2} / \mathrm{g}$, accompanied by the surge of mesoporous surface area $\left(1926 \mathrm{~m}^{2} / \mathrm{g}\right)$. This implies that the skeleton structure of sugarcane began to collapse under 9 wt.\% sulfuric acid, resulting to the vanishment and blocking of micropores (Yang et al. 2020). The pore size distribution of the samples has a similar tendency with $S_{\mathrm{BET}}$ (Fig. 2b). It was recognized that the micropore played a decisive role in VOCs adsorption, especially when the VOCs concentration is low (Guo et al. 2020). Besides, the diffusion of VOC molecule is well situated to benefit from the presence of mesopores. Therefore, the SBAC-7 sample treated with the optimized acid concentration is better at keeping micropores and considerable amount of mesopores, which will own more excellent adsorption property. 
3. As shown in Fig. 3a and $\mathbf{b}$, the SBAC-0 was in the shape of a fiber block with rough surface and few pores on the surface. After the hydrothermal carbonation in certain concentrations of sulfuric acid solution (i.e., 3 7 wt.\%), the biochar could maintain the vascular bundle structure

(Fig. 3c to h), which proved that the cage construction of SB precursor has a good corrosion resistance. However, when further increase the acid concentration to 9 wt.\% (Fig. 3i and j), the pore diameter of SBAC-9 began to increase and the carbon skeleton was found to dilapidated and hollowed, which finally led to a decrease in micropore surface area (Wang et al. 2018b). This result is highly consistent with the $\mathrm{N}_{2}$ sorption isotherms. In addition, the acid-treated

SBAC-x have more smooth surface, which could be due to the cleaning effect of sulfuric acid solution for the surface impurities (Tang et al. 2016). Note that the etching between sulfuric to the stretching vibration of dissociative O-H group. The spectra showed strong absorption peak at $3435 \mathrm{~cm}^{-1}$ represented the $\mathrm{O}-\mathrm{H}$ stretching vibration in carboxyl and phenol (Pezoti et 
al. 2016). The band located at $2362 \mathrm{~cm}^{-1}$ was attributed to the $\mathrm{C}=\mathrm{O}$ stretching vibration, which was due to carbon dioxide in the air. The peak located at $1721 \mathrm{~cm}^{-1}$ was related to the $\mathrm{C}=\mathrm{O}$ stretching vibration in aliphatic ketone, which appeared after the addition of sulfuric acid. The band at 1630 and $1400 \mathrm{~cm}^{-1}$ correspond to the antisymmetric and symmetric stretching vibrations of -COO- group. The bands located at $1120 \mathrm{~cm}^{-1}$ and $830 \mathrm{~cm}^{-1}$ were connected with sulfur-containing functional groups, which was symmetrical stretching vibration of $\mathrm{O}=\mathrm{S}=\mathrm{O}$ and C-O-S, respectively. And with the increase of sulfuric acid concentration, these two peaks became more obvious. The peaks at 1581 and $1123 \mathrm{~cm}^{-1}$ were $-\mathrm{SO}_{2}$ - and $\mathrm{S}=\mathrm{O}$ stretching vibration, which appeared while sulfuric acid concentration reached $7 \mathrm{wt} . \%$. It could be easily observed that the number of sulfur-containing functional groups increased with the increase of sulfuric acid concentration. At the same time, the types and number of oxygen-containing functional groups also increased, which might change the surface charge, hydrophilicity, polarity and other surface chemical properties of the as-prepared biochar.

In order to further study the existing state of surface elements of activated carbons, XPS analysis method was adopted and the results were shown in Fig. 5 and Table 2. The survey spectra of all the as-prepared activated carbons contain $\mathrm{C} 1 \mathrm{~s}, \mathrm{O}$ 1s and $\mathrm{S} 2 \mathrm{p}$ spectra. The sulfur content of SBAC-0 was only $0.25 \%$, which was due to the biological uptake by sugarcane growth. After sulfuric acid treatment, the surface S content increased to some extent, which indicated that the sulfur element had loaded on the surface of biochar during preparation. Meanwhile, carbon content decreased and oxygen content increased with sulfuric acid concentration increased. The XPS C 1s spectra of the samples shows three peaks at the binding energies of $284.7,286.3$ and $289.3 \mathrm{eV}$, which were related to $\mathrm{C}-\mathrm{C}, \mathrm{C}-\mathrm{O}$ and $\mathrm{O}=\mathrm{C}-\mathrm{OH}$, 
respectively (Cheng et al. 2020, Wang et al. 2019). The deconvoluted XPS S 2p signals at binding energies of $160.0,164.3,165.3$ and $168.9 \mathrm{eV}$ corresponded to functional groups such as $\mathrm{S}^{2-}$, disulfide (C-S-S-C), sulfinyl group $\left(\mathrm{C}_{2} \mathrm{~S}=\mathrm{O}\right)$, sulfone $\left(\mathrm{C}_{2} \mathrm{~S}\left(=\mathrm{O}_{2}\right)\right)$ reported in previous studies (Grzybek et al. 2004, Ting et al. 2018). The XPS O 1s spectra, which were shown in Fig. 5c, can be disassembled into three peaks. The peak at the binding energies of $531.5 \mathrm{eV}$ was ascribed to $\mathrm{O}=\mathrm{C}$ of ketone, carbonyl and/or lactone groups. The band observed at 532.3 $\mathrm{eV}$ was assigned to $\mathrm{C}-\mathrm{O}$ in ether and/or alcohol. And the peak located at $533.3 \mathrm{eV}$ was corresponded to $\mathrm{O}=\mathrm{C}-\mathrm{OH}$ (Goel et al. 2015, Guo et al. 2020). It is believed that $\mathrm{O}=\mathrm{C}$ and $\mathrm{C}-\mathrm{O}$ were responsible for surface basicity and $\mathrm{O}=\mathrm{C}-\mathrm{OH}$ reflected the surface acidity (Tiwari et al. 2018). The surface adsorption active sites of biochar were related to the surface functional group as mentioned above (Vega et al. 2013a). The amount and proportion of surface basicity increased with the rose of sulfuric acid concentration, which lead to a rise in $\mathrm{pH}_{\mathrm{pzc}}$ of zero potential point on the surface, thus enhancing the non-polarity of the activated carbon. Additionally, toluene was a weak or non-polar molecule. The increased surface basicity can promote the adsorption capacity of toluene by increasing the $\pi-\pi$ electron diffusion capability on the biochar.

\subsection{Adsorption capacity of the biochar}

The dynamic adsorption behaviors of toluene on different samples were considered and the breakthrough curves were presented in Fig. 6. The corresponding saturated adsorption capacity was $387.6,641.4,695.0,771.7$ and $711.8 \mathrm{mg} / \mathrm{g}$ from 0 to $9 \mathrm{wt} . \%$ of sulfuric acid, respectively. Apparently, above results agreed with the textural properties (specific surface area and pore properties) and surface functionalities (amount and proportion of surface groups). Besides, 
breakthrough time was defined as the time when outlet toluene concentration reached $1 \%$ of feed concentration, which was more commonly used in practical applications. For the SBACx samples, the breakthrough time was 16, 44, 60, 68 and $60 \mathrm{~min}$, respectively. As is known, the adsorption capacity of commercial activated carbon is usually at 200 to $300 \mathrm{mg} / \mathrm{g}$, which is only one third of our best sample (SBAC-7). Table 3 compared the toluene adsorption capacity of the as-prepared SBAC-7 with those of other carbon-based adsorbent reported in the literature, which also indicate the excellent adsorption capacity of SBAC-7 in this work. As described in Fig. 2 and Table 1, the specific surface area and ratio of micropore reaches the maximum value when sulfuric acid was added at $7 \mathrm{wt} . \%$. Meanwhile, the carbon skeleton and surface structure were the most abundant. In addition, as shown in Fig. $\mathbf{5}$ and Table 2, the addition of sulfuric acid enhanced the surface basicity. These suggest that the pore structure and surface functional groups are the core factors to improve the adsorption capacity of biochar for toluene.

Although the adsorption capacity of adsorbent is important, the desorption capacity which determine the regeneration effect is also noteworthy. The common method of desorption is treatment in high temperature with $\mathrm{N}_{2}$ or water vapour, which means that the lower temperature and higher desorption efficiency could reduce energy consumption as much as possible. In order to understand the regeneration process, desorption test of SBAC-0 and SBAC-7 was compared and the result was shown in Fig. 7. On both samples the desorption peak appeared at $90{ }^{\circ} \mathrm{C}$, which was much lower than the previously reported $110{ }^{\circ} \mathrm{C}$ (Zhu et al. 2020). Moreover, the carbon balance of SBAC-7 (ca. 98.7\%) was much higher than SBAC-0 (ca. 73.6\%). This may be explained by the existence of mesopores which promoted toluene transfer and suitable adsorption strength due to the huge amount of S-containing functional groups. 
performed as shown in Fig. 8. The regeneration temperature in each cycle was set at $90{ }^{\circ} \mathrm{C}$ change remarkably during the five cycles. The saturation adsorption capacity was $771.7,759.7$, compare that to the first time. Analysis of the reactor effluent at the desorption steps during the five cycles confirmed that the toluene was desorbed completely. This is proved by the excellent carbon balances obtained during cycling ( $>96 \%)$. These results imply that SBAC-7 was renewable, reusable and recyclable during the adsorption-desorption cycle.

\subsection{Adsorption kinetics model} were detail described as follows.

(1) Pseudo-first order model

where $\mathrm{q}_{\mathrm{t}}$ and $\mathrm{q}_{\mathrm{e}}$ was the amount of toluene adsorption at time $\mathrm{t}$ and equilibrium $(\mathrm{mg} / \mathrm{g})$, and $\mathrm{k}_{1}$ was the quasi-second-order rate constant $\left(\mathrm{min}^{-1}\right)$.

(2) Pseudo-second order model

$$
q_{t}=q_{e}\left(1-e^{-k_{1} t}\right)
$$

where $\mathrm{k}_{2}$ is the quasi-second-order rate constant $\left(\mathrm{min}^{-1}\right)$.

$$
q_{t}=\frac{k_{2} q_{e}^{2} t}{1+k_{2} q_{e} t}
$$


277 Where $\alpha$ is the initial adsorption rate constant $\left(\mathrm{mg} \mathrm{g}^{-1} \mathrm{~min}^{-1}\right)$ and $\beta$ is the desorption rate constant $(\mathrm{g} / \mathrm{mg})$.

(4) Bangham model

$$
q_{t}=q_{e}-\frac{q_{e}}{e^{k t^{z}}}
$$

where $\mathrm{k}$ is the Bangham constant $\left(\mathrm{min}^{-1}\right)$ and $\mathrm{z}$ is a constant.

The fitting curve and estimated parameters are shown in Fig. 9 and Table 4. It can be easily found that only the Bangham model was well fitting and the correlation coefficients $\left(\mathrm{R}_{2}\right)$ were $<0.99$. Meanwhile, the adsorption capacity predicted by this model was closer to the actual measured value, from which we can conclude that the Bangham model was the best model for toluene adsorption in as-prepared samples. It revealed that toluene adsorption involved two parts: toluene adsorption at the surface and diffusion in the pores (Lei et al. 2020). Moreover, the intraparticle diffusion played a major role, which could affect the adsorption rate (Gong et al. 2019).

\section{Conclusions}

In short, we presented a facile in-situ modification method for biochar with excellent performance. The as-prepared biochar owned high specific surface areas, great pore volumes and abundant surface chemical group. SBAC-7 exhibited the best toluene adsorption capacity of $771.7 \mathrm{mg} / \mathrm{g}$, which was about 3 times higher than that of commercial ACs, while retaining mild flexibility. Meanwhile, it showed considerable stability and cyclic regeneration performance with five toluene adsorption-desorption test cycles. The outstanding performance was associated with its superior physicochemical properties. On one hand, etching effect of 
sulfuric acid were conducive to higher specific surface area $\left(2245 \mathrm{~m}^{2} / \mathrm{g}\right)$ and formation of more micropores. Others, the surface S-containing functional groups surged by adding sulfuric acid, which enhancing the surface basicity and non-polarity of the biochar. These factors simultaneously promoted the adsorption and internal diffusion of toluene molecule. This work provided a valuable guide to produce applicable adsorbents with agricultural wastes for the adsorption of toluene in the practical implications.

\section{Acknowledgments}

The present work is supported by Scientific Research Program Guidance Project of Hubei Province (No. B2020210) and Natural Science Foundation of Hubei Province (2019CFA070).

\section{Conflict of interest}

The authors declare that they have no conflict of interests.

\section{Ethical approval}

The article is original. The manuscript has not been published previously by any of the authors, is not under consideration for publication in any other journal at the time of submission, will not be submitted elsewhere before one decision is made. No conflict of interest exists. If accepted, the article will not be published elsewhere in the same form, in any language, without the written consent of the publisher.

\section{Consent to participate}

All authors have participated in the study works.

\section{Consent to publish}

All authors are aware of the submission and agree to its publication.

\section{Authors Contributions}


Yi Chen carried out materials syntheses. Yuan Qu, Yi Chen and Shikuan Sun performed all activity tests and related measurements and interpretation of results. Yuan Qu amd Yi Chen performed the original draft. All authors discussed the results and edited the manuscript. All authors reviewed and approved the manuscript. Limin Guo supervised the study.

325

\section{Funding}

The present work is funded by Scientific Research Program Guidance Project of Hubei Province (No. B2020210) and Natural Science Foundation of Hubei Province (2019CFA070).

\section{Data availability}

All data generated or analyzed during this study are included in this published article.

\section{References}

Alslaibi TM, Abustan I, Ahmad MA, Foul AA(2013): A review: production of activated carbon from agricultural byproducts via conventional and microwave heating. Journal of Chemical Technology \& Biotechnology 88, 1183-1190

Chen H, Wang H, Xue Z, Yang L, Xiao Y, Zheng M, Lei B, Liu Y, Sun L (2012): High hydrogen storage capacity of rice hull based porous carbon. Int. J. Hydrogen Energy 37, 1888818894

Cheng H, Sun Y, Wang X, Zou S, Ye G, Huang H, Ye D (2020): Hierarchical porous carbon fabricated from cellulose-degrading fungus modified rice husks: Ultrahigh surface area and impressive improvement in toluene adsorption. J. Hazard. Mater. 392, 122298

Gao Y, Li L, Jin Y, Wang Y, Yuan C, Wei Y, Chen G, Ge J, Lu H (2015): Porous carbon made from rice husk as electrode material for electrochemical double layer capacitor. Appl. 
Goel C, Bhunia H, Bajpai PK (2015): Synthesis of nitrogen doped mesoporous carbons for carbon dioxide capture. RSC Advances 5, 46568-46582

Gong H, Liu W, Liu L, Goyal N, Xiao P, Li G, Wei Y, Du T (2019): In-situ synthesis of an excellent CO2 capture material chabazite. J. Taiwan Inst. Chem. Eng. 103, 160-166

Grzybek T, Pietrzak R, Wachowska H (2004): The Comparison of Oxygen and Sulfur Species Formed by Coal Oxidation with O2/Na2CO3or Peroxyacetic Acid Solution. XPS Studies. Energy \& fuels 18, 804-809

Guo Y, Tan C, Sun J, Li W, Zhang J, Zhao C (2020): Porous activated carbons derived from waste sugarcane bagasse for CO2 adsorption. Chem. Eng. J. 381, 122736

He C, Cheng J, Zhang X, Douthwaite M, Pattisson S, Hao Z (2019): Recent Advances in the Catalytic Oxidation of Volatile Organic Compounds: A Review Based on Pollutant Sorts and Sources. Chem. Rev. 119, 4471-4568

Hossein Tehrani NHM, Alivand MS, Rashidi A, Rahbar Shamskar K, Samipoorgiri M, Esrafili MD, Mohammady Maklavany D, Shafiei-Alavijeh M (2020): Preparation and characterization of a new waste-derived mesoporous carbon structure for ultrahigh adsorption of benzene and toluene at ambient conditions. J Hazard Mater 384, 121317

Hu L, Peng Y, Wu F, Peng S, Li J, Liu Z (2017): Tubular activated carbons made from cotton stalk for dynamic adsorption of airborne toluene. J. Taiwan Inst. Chem. Eng. 80, 399405

Huang J, Khan MT, Perecin D, Coelho ST, Zhang M (2020a): Sugarcane for bioethanol production: Potential of bagasse in Chinese perspective. Renewable Sustainable Energy 
Huang S, Deng W, Zhang L, Yang D, Gao Q, Tian Z, Guo L, Ishihara T (2020b): Adsorptive properties in toluene removal over hierarchical zeolites. Microporous Mesoporous Mater. 302, 110204

Jain A, Balasubramanian R, Srinivasan MP (2016): Hydrothermal conversion of biomass waste to activated carbon with high porosity: A review. Chem. Eng. J. 283, 789-805

Jin Z, Wang B, Ma L, Fu P, Xie L, Jiang X, Jiang W (2020): Air pre-oxidation induced high yield N-doped porous biochar for improving toluene adsorption. Chem. Eng. J. 385, 123843

Kim K-J, Kang C-S, You Y-J, Chung M-C, Woo M-W, Jeong W-J, Park N-C, Ahn H-G (2006): Adsorption-desorption characteristics of VOCs over impregnated activated carbons. Catal. Today $111,223-228$

Lei B, Liu B, Zhang H, Yan L, Xie H, Zhou G (2020): CuO-modified activated carbon for the improvement of toluene removal in air. Journal of Environmental Sciences 88, 122-132

Li X, Zhang L, Yang Z, Wang P, Yan Y, Ran J (2020): Adsorption materials for volatile organic compounds (VOCs) and the key factors for VOCs adsorption process: A review. Sep. Purif. Technol. 235, 116213

Oliveira JA, Cunha FA, Ruotolo LAM (2019): Synthesis of zeolite from sugarcane bagasse fly ash and its application as a low-cost adsorbent to remove heavy metals. Journal of Cleaner Production 229, 956-963

Pak S-H, Jeon M-J, Jeon Y-W (2016): Study of sulfuric acid treatment of activated carbon used to enhance mixed VOC removal. International Biodeterioration \& Biodegradation 113, 
Pezoti O, Cazetta AL, Bedin KC, Souza LS, Martins AC, Silva TL, Santos Júnior OO, Visentainer JV, Almeida VC (2016): NaOH-activated carbon of high surface area produced from guava seeds as a high-efficiency adsorbent for amoxicillin removal: Kinetic, isotherm and thermodynamic studies. Chem. Eng. J. 288, 778-788

Qie Z, Sun F, Zhang Z, Pi X, Qu Z, Gao J, Zhao G (2020): A facile trace potassium assisted catalytic activation strategy regulating pore topology of activated coke for combined removal of toluene/SO2/NO. Chem. Eng. J. 389, 124262

Shen Y, Zhang N (2019): Facile synthesis of porous carbons from silica-rich rice husk char for volatile organic compounds (VOCs) sorption. Bioresource Technology 282, 294-300

Shi X, Zhang X, Bi F, Zheng Z, Sheng L, Xu J, Wang Z, Yang Y (2020): Effective toluene adsorption over defective UiO-66-NH2: An experimental and computational exploration. J. Mol. Liq. 316, 113812

Shu Y, He M, Ji J, Huang H, Liu S, Leung DYC (2019): Synergetic degradation of VOCs by vacuum ultraviolet photolysis and catalytic ozonation over Mn-xCe/ZSM-5. J. Hazard. Mater. 364, 770-779

Tang L, Li L, Chen R, Wang C, Ma W, Ma X (2016): Adsorption of acetone and isopropanol on organic acid modified activated carbons. Journal of Environmental Chemical Engineering 4, 2045-2051

Tang M, Huang X, Peng Y, Lu S (2020): Hierarchical porous carbon as a highly efficient adsorbent for toluene and benzene. Fuel 270, 117478

Tham YJ, Latif PA, Abdullah AM, Shamala-Devi A, Taufiq-Yap YH (2011): Performances of 

toluene removal by activated carbon derived from durian shell. Bioresource Technology $102,724-728$

Ting Y, Chen C, Ch'ng B-L, Wang Y-L, Hsi H-C (2018): Using raw and sulfur-impregnated activated carbon as active cap for leaching inhibition of mercury and methylmercury from contaminated sediment. J Hazard Mater 354, 116-124

Tiwari D, Bhunia H, Bajpai PK (2018): Adsorption of CO2 on KOH activated, N-enriched carbon derived from urea formaldehyde resin: kinetics, isotherm and thermodynamic studies. Appl. Surf. Sci. 439, 760-771

Vega E, Lemus J, Anfruns A, Gonzalez-Olmos R, Palomar J, Martin MJ (2013a): Adsorption of volatile sulphur compounds onto modified activated carbons: effect of oxygen functional groups. J. Hazard. Mater. 258-259, 77-83

Vega E, Lemus J, Anfruns A, Gonzalez-Olmos R, Palomar J, Martin MJ (2013b): Adsorption of volatile sulphur compounds onto modified activated carbons: Effect of oxygen functional groups. J Hazard Mater 258-259, 77-83

Wang S, Nam H, Nam H (2020a): Preparation of activated carbon from peanut shell with KOH activation and its application for $\mathrm{H} 2 \mathrm{~S}$ adsorption in confined space. Journal of Environmental Chemical Engineering 8, 103683

Wang T, Zhai Y, Zhu Y, Li C, Zeng G (2018a): A review of the hydrothermal carbonization of biomass waste for hydrochar formation: Process conditions, fundamentals, and physicochemical properties. Renewable Sustainable Energy Rev. 90, 223-247

Wang T, Zhu J, Wei Z, Yang H, Ma Z, Ma R, Zhou J, Yang Y, Peng L, Fei H, Lu B, Duan X (2019): Bacteria-Derived Biological Carbon Building Robust Li-S Batteries. Nano Lett. 
Wang Y, Yang D, Li S, Chen M, Guo L, Zhou J (2018b): Ru/hierarchical HZSM-5 zeolite as efficient bi-functional adsorbent/catalyst for bulky aromatic VOCs elimination. Microporous Mesoporous Mater. 258, 17-25

Wang Y, Chen Y, Zhang L, Wang G, Deng W, Guo L (2020b): Total catalytic oxidation of chlorinated aromatics over bimetallic Pt-Ru supported on hierarchical HZSM-5 zeolite. Microporous Mesoporous Mater. 308, 110538

Wang Y, Liu K, Wu J, Hu Z, Huang L, Zhou J, Ishihara T, Guo L (2020c): Unveiling the Effects of Alkali Metal Ions Intercalated in Layered $\mathrm{MnO} 2$ for Formaldehyde Catalytic Oxidation. ACS Catal. 10, 10021-10031

Wang Y, Wu J, Wang G, Yang D, Ishihara T, Guo L (2021): Oxygen Vacancy Engineering in Fe Doped Akhtenskite-Type MnO2 for Low-Temperature Toluene Oxidation. Appl. Catal. B: Environ. 285, 119873

Yang D, Fu S, Huang S, Deng W, Wang Y, Guo L, Ishihara T (2020): The preparation of hierarchical Pt/ZSM-5 catalysts and their performance for toluene catalytic combustion. Microporous Mesoporous Mater. 296, 109802

Zhang X, Gao B, Fang J, Zou W, Dong L, Cao C, Zhang J, Li Y, Wang H (2019): Chemically activated hydrochar as an effective adsorbent for volatile organic compounds (VOCs). Chemosphere (Oxford) 218, 680-686

Zhao X, Zeng X, Qin Y, Li X, Zhu T, Tang X (2018): An experimental and theoretical study of the adsorption removal of toluene and chlorobenzene on coconut shell derived carbon. Chemosphere 206, 285-292 
452 Zhou K, Ma W, Zeng Z, Ma X, Xu X, Guo Y, Li H, Li L (2019): Experimental and DFT study 453 on the adsorption of VOCs on activated carbon/metal oxides composites. Chem. Eng. $454 \quad$ J. $372,1122-1133$

455 Zhu J, Li Y, Xu L, Liu Z (2018): Removal of toluene from waste gas by adsorption-desorption 456 process using corncob-based activated carbons as adsorbents. Ecotoxicology and 457 Environmental Safety $165,115-125$

Zhu L, Shen D, Luo KH (2020): A critical review on VOCs adsorption by different porous materials: Species, mechanisms and modification methods. J. Hazard. Mater. 389,

460 122102

461 


\section{$463 \quad$ Figure captions}

464 Figure 1. XRD patterns of the as-prepared samples.

465 Figure 2. (a) $\mathrm{N}_{2}$ sorption isotherms and (b) pore-size distributions of the as-prepared samples.

466 Figure 3. SEM images of as-prepared activated carbon samples SBAC-0 (a, b), SBAC-3 (c, d), 467 SBAC-5 (e, f), SBAC-7 (g, h), and SBAC-9 (i, j).

468 Figure 4. FT-IR spectra of the as-prepared samples.

469 Figure 5. (a) C 1s, (b) S 2p and (c) O 1s XPS spectra of the as-prepared samples.

470 Figure 6. Adsorption breakthrough curves of as-prepared samples.

471 Figure 7. Desorption curves of SBAC-0 (a) and SBAC-7 (b).

472 Figure 8. The consecutive toluene adsorption-desorption cycles of SBAC-7.

473 Figure 9. Adsorption kinetics model fit adsorption curve: (a) Pseudo-first-order model, (b)

474 Pseudo-second-order model, (c) Elovich model, (d) Bangham model. 


\section{Tables}

477 Table 1. BET surface areas and pore volumes of the as-prepared samples.

\begin{tabular}{lllllll}
\hline Samples & $\begin{array}{l}S_{\mathrm{BET}^{a}} \\
\left(\mathrm{~m}^{2} / \mathrm{g}\right)\end{array}$ & $\begin{array}{l}S_{\mathrm{mic}^{b}} \\
\left(\mathrm{~m}^{2} / \mathrm{g}\right)\end{array}$ & $\begin{array}{l}S_{\text {mes }} \\
\left(\mathrm{m}^{2} / \mathrm{g}\right)\end{array}$ & $\begin{array}{l}\mathrm{V}_{\mathrm{t}}^{c} \\
\left(\mathrm{~cm}^{3} / \mathrm{g}\right)\end{array}$ & $\begin{array}{l}\mathrm{V}_{\mathrm{mic}^{b}} \\
\left(\mathrm{~cm}^{3} / \mathrm{g}\right)\end{array}$ & $\begin{array}{l}\mathrm{V}_{\mathrm{mes}} \\
\left(\mathrm{cm}^{3} / \mathrm{g}\right)\end{array}$ \\
\hline SBAC-0 & 1137 & 929 & 208 & 0.76 & 0.48 & 0.28 \\
SBAC-3 & 2154 & 768 & 1386 & 1.24 & 0.43 & 0.81 \\
SBAC-5 & 2215 & 636 & 1579 & 1.24 & 0.36 & 0.88 \\
SBAC-7 & 2455 & 1106 & 1349 & 1.26 & 0.53 & 0.73 \\
SBAC-9 & 2122 & 196 & 1926 & 1.28 & 0.12 & 1.16 \\
\hline
\end{tabular}

478

${ }^{a}$ Specific surface area calculated by BET method at $P / P_{0}=0.05-0.30$.

$479 \quad{ }^{b}$ Micropore evaluated by t-plot method.

$480{ }^{c}$ Total pore volume obtained from the single point adsorption volume at $P / P_{0}=0.995$.

481

482

483

484 
485 Table 2. Quantitative characterization of the surface compositions of the as-prepared samples.

\begin{tabular}{lllllll}
\hline Samples & \multicolumn{3}{l}{ Surface atomic (\%) } & \multicolumn{4}{l}{ Peak area ratio (\%) } \\
\cline { 2 - 7 } & C 1s & S 2p & O 1s & C=O/O1s & C-O/O1s & COOH/O1s \\
\hline SBAC-0 & 95.33 & 0.25 & 4.42 & 12.47 & 28.27 & 59.26 \\
SBAC-3 & 94.96 & 0.42 & 4.62 & 3.12 & 42.91 & 53.97 \\
SBAC-5 & 94.61 & 1.18 & 4.21 & 5.42 & 43.06 & 51.52 \\
SBAC-7 & 90.25 & 2.71 & 7.04 & 33.04 & 25.76 & 41.20 \\
SBAC-9 & 86.23 & 2.56 & 11.21 & 26.51 & 37.12 & 36.37 \\
\hline
\end{tabular}

486 
Table 3. Toluene adsorption capacity reported in the literature.

\begin{tabular}{|c|c|c|c|c|c|}
\hline Materials & Experiment conditions & $\begin{array}{l}\mathrm{S}_{\mathrm{BET}} \\
\left(\mathrm{m}^{2} / \mathrm{g}\right)\end{array}$ & $\begin{array}{l}\text { Adsorption } \\
\text { capacity }(\mathrm{mg} / \mathrm{g})\end{array}$ & $\begin{array}{l}\text { Breakthrough time } \\
\text { (min) }\end{array}$ & Reference \\
\hline $10 \mathrm{~S}-\mathrm{AC}$ & $150 \mathrm{ppm}, 6 \mathrm{~L} \mathrm{~min}^{-1}$, room temperature & 840 & 123 & 240 & (Pak et al. 2016) \\
\hline Commercial AC & $10.0 \mathrm{~g} \mathrm{~m}^{-3}, 50 \mathrm{~mL} \mathrm{~min}^{-1}, 298 \mathrm{~K}$ & 934 & 41 & 100 & (Zhou et al. 2019) \\
\hline $\mathrm{AC} / \mathrm{MgO}$ & $10.0 \mathrm{~g} \mathrm{~m}^{-3}, 50 \mathrm{~mL} \mathrm{~min}^{-1}, 298 \mathrm{~K}$ & 794 & 56 & 110 & (Zhou et al. 2019) \\
\hline $\mathrm{AC} / \mathrm{ZnO}$ & $10.0 \mathrm{~g} \mathrm{~m}^{-3}, 50 \mathrm{~mL} \mathrm{~min}^{-1}, 298 \mathrm{~K}$ & 847 & 68 & 130 & (Zhou et al. 2019) \\
\hline $\mathrm{AC} / \mathrm{CuO}$ & $10.0 \mathrm{~g} \mathrm{~m}^{-3}, 50 \mathrm{~mL} \mathrm{~min}{ }^{-1}, 298 \mathrm{~K}$ & 769 & 46 & 130 & (Zhou et al. 2019) \\
\hline $\mathrm{AC} / \mathrm{ZrO}_{2}$ & $10.0 \mathrm{~g} \mathrm{~m}^{-3}, 50 \mathrm{~mL} \mathrm{~min}^{-1}, 298 \mathrm{~K}$ & 837 & 127 & 120 & (Zhou et al. 2019) \\
\hline $\mathrm{AC}$ (rice husk) & 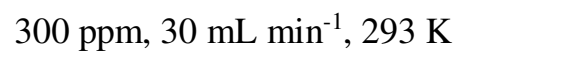 & 1818 & 264 & 2784 & (Shen \&Zhang 2019) \\
\hline CBAC-1.0-1.0-550 & $3000 \mathrm{mg} \mathrm{m}^{-3}, 500 \mathrm{ml} \mathrm{min}^{-1}, 298 \mathrm{~K}$ & 1501 & 414.6 & 72 & (Zhu et al. 2018) \\
\hline $\mathrm{AC}$ (petroleum waste) & $10 \%, 125 \mathrm{~mL} \mathrm{~min}^{-1}, 298 \mathrm{~K}$ & 2692 & 659.9 & 65 & (Hossein Tehrani et al. 2020) \\
\hline CAC & 80 ppm, $2 \mathrm{~L} \mathrm{~min}^{-1}, 303 \mathrm{~K}$ & 1011 & 189 & 348 & (Zhao et al. 2018) \\
\hline $\mathrm{CDC}$ & 80 ppm, $2 \mathrm{~L} \mathrm{~min}{ }^{-1}, 303 \mathrm{~K}$ & 1137 & 255 & 544 & (Zhao et al. 2018) \\
\hline $\mathrm{UiO}-66-\mathrm{NH} 2$ & 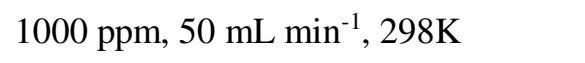 & 568 & 162 & 148 & (Shi et al. 2020) \\
\hline C-U-N-0.5 & 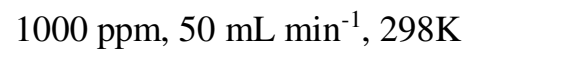 & 795 & 228 & 228 & (Shi et al. 2020) \\
\hline $\mathrm{BP}(350 / 120 / 2)$ & 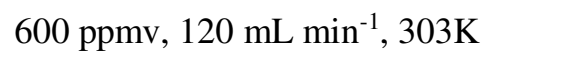 & 762.9 & 352.7 & 282 & (Jin et al. 2020) \\
\hline KP-AC-2 & 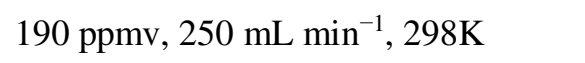 & 1283.6 & 300.3 & 200 & (Qie et al. 2020) \\
\hline AC-P & $1000 \mathrm{ppm}, 150 \mathrm{~mL} \mathrm{m^{-1 }}, 298 \mathrm{~K}$ & 1256 & 328 & 300 & (Hu et al. 2017) \\
\hline $\mathrm{AC}-\mathrm{Z}$ & 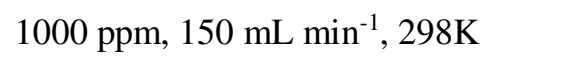 & 795 & 258 & 300 & (Hu et al. 2017) \\
\hline NHPC-900 & 600 ppm, $200 \mathrm{~mL} \mathrm{~min}{ }^{-1}, 303 \mathrm{~K}$ & 778 & 272 & 54 & (Tang et al. 2020) \\
\hline HPC-900 & 600 ppm, $200 \mathrm{~mL} \mathrm{~min}{ }^{-1}, 303 \mathrm{~K}$ & 578 & 182 & 36 & (Tang et al. 2020) \\
\hline SBAC-7 & $1000 \mathrm{ppm}, 100 \mathrm{~mL} \mathrm{~min}{ }^{-1}, 303 \mathrm{~K}$ & 2455 & 771.7 & 80 & This work \\
\hline
\end{tabular}


Table 4. Adsorption kinetics fitting parameters of toluene adsorption on as-prepared samples.

\begin{tabular}{|c|c|c|c|c|c|c|c|c|c|c|c|}
\hline \multirow[t]{2}{*}{ Samples } & \multicolumn{2}{|c|}{$\begin{array}{l}\text { Pseudo-first order } \\
\text { model }\end{array}$} & \multicolumn{2}{|c|}{$\begin{array}{l}\text { Pseudo-second order } \\
\text { model }\end{array}$} & \multicolumn{2}{|c|}{ Elovich model } & \multicolumn{3}{|c|}{ Bangham model } & & \multirow[t]{2}{*}{$\begin{array}{l}\mathrm{q}_{\mathrm{e}} \\
(\mathrm{mg} / \mathrm{g})\end{array}$} \\
\hline & $\mathrm{k}_{1}$ & $\mathrm{R}^{2}$ & $\mathrm{k}_{2}$ & $\mathrm{R}^{2}$ & $\alpha$ & $\beta$ & $\mathrm{R}^{2}$ & $\mathrm{k}$ & $\mathrm{Z}$ & $\mathrm{R}^{2}$ & \\
\hline SBAC-0 & 0.0945 & 0.911 & $5.32 * 10^{-5}$ & 0.939 & 37.196 & $7.96 * 10^{-3}$ & 0.948 & $1.16^{*} 10^{-2}$ & 1.397 & 0.999 & 387.6 \\
\hline SBAC-3 & 0.0766 & 0.867 & $4.39 * 10^{-6}$ & 0.754 & 38.191 & $4.21 * 10^{-3}$ & 0.939 & $4.19 * 10^{-3}$ & 1.484 & 0.996 & 641.4 \\
\hline SBAC-5 & 0.0753 & 0.881 & $1.87 * 10^{-6}$ & 0.635 & 38.960 & $3.81 * 10^{-3}$ & 0.921 & $3.13^{*} 10^{-3}$ & 1.529 & 0.993 & 695.0 \\
\hline SBAC-7 & 0.0741 & 0.763 & $1.85 * 10^{-6}$ & 0.620 & 39.527 & $3.46^{*} 10^{-3}$ & 0.905 & $3.3 * 10^{-3}$ & 1.442 & 0.993 & 771.7 \\
\hline SBAC-9 & 0.0773 & 0.851 & $4.44 * 10^{-7}$ & 0.523 & 39.051 & $3.73 * 10^{-3}$ & 0.919 & $3.22 * 10^{-3}$ & 1.505 & 0.993 & 711.8 \\
\hline
\end{tabular}


Figure 1

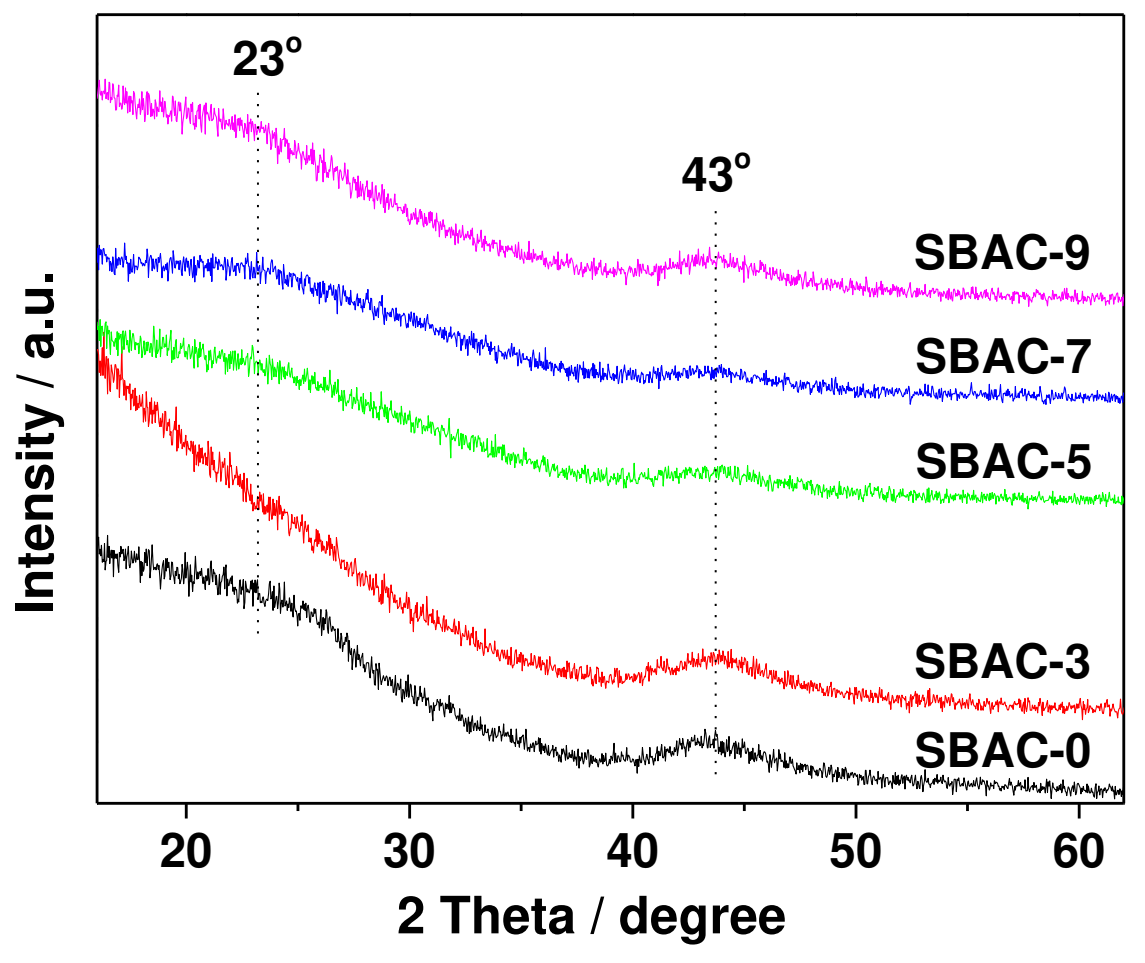


Figure 2
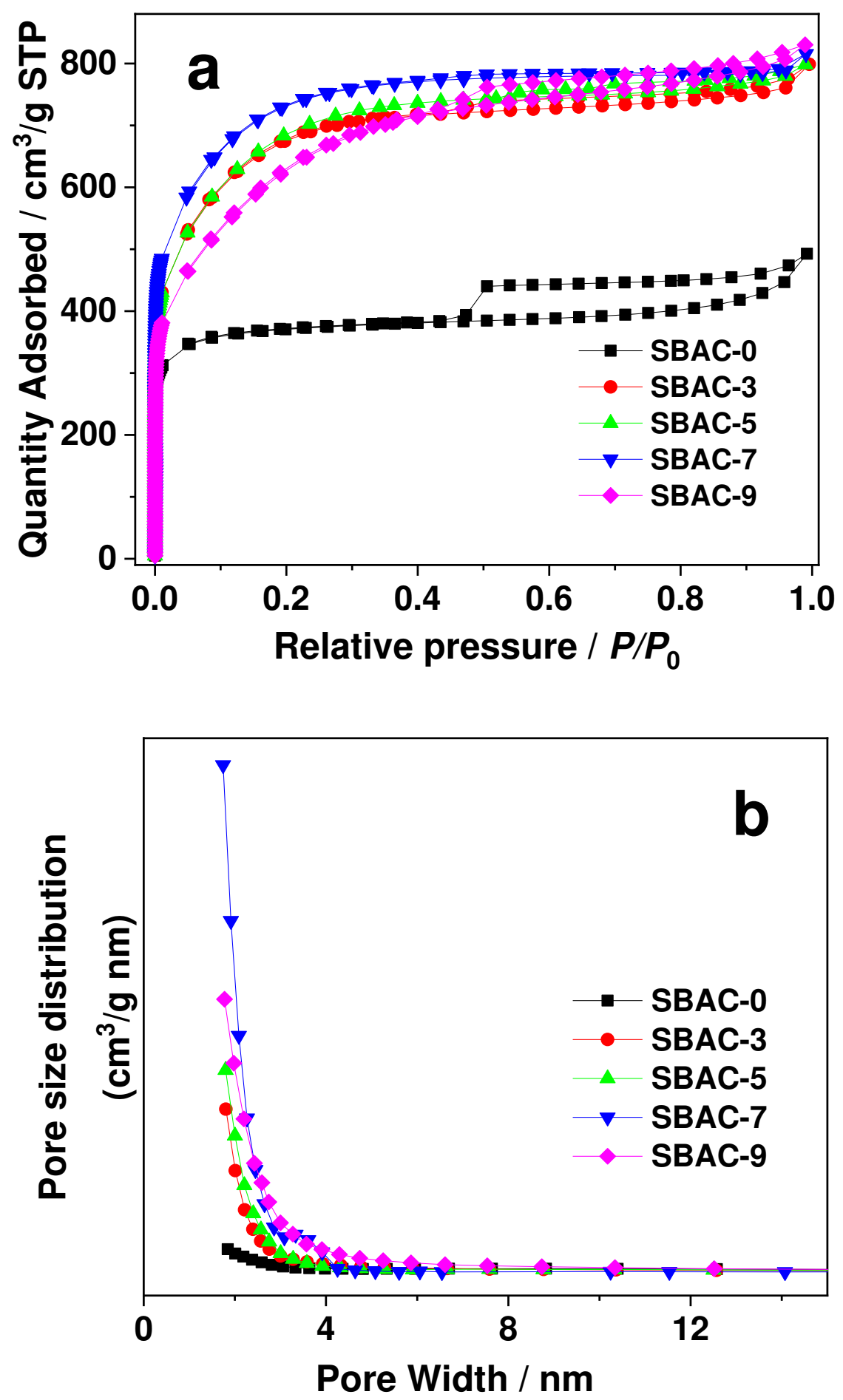
Figure 3

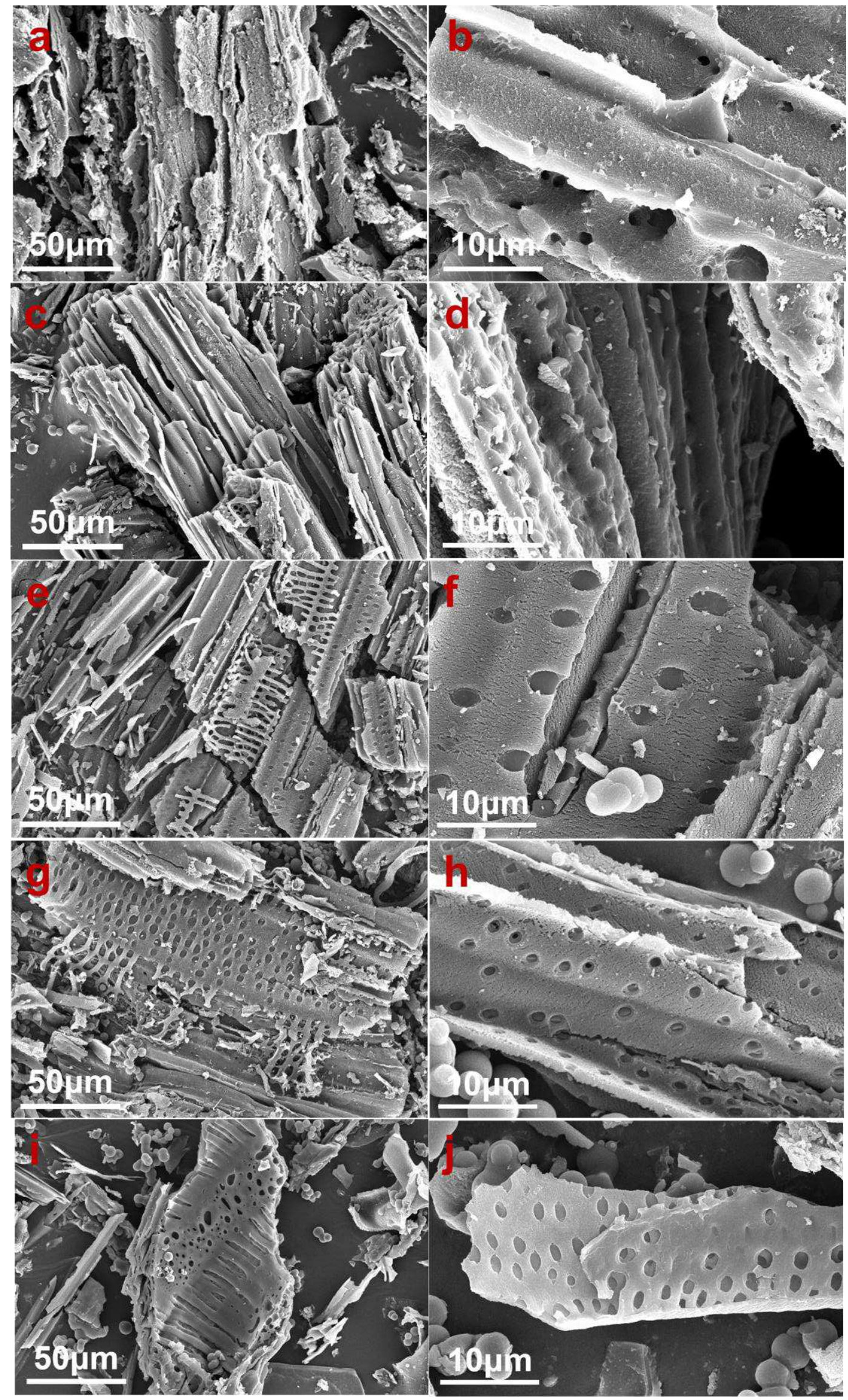


Figure 4

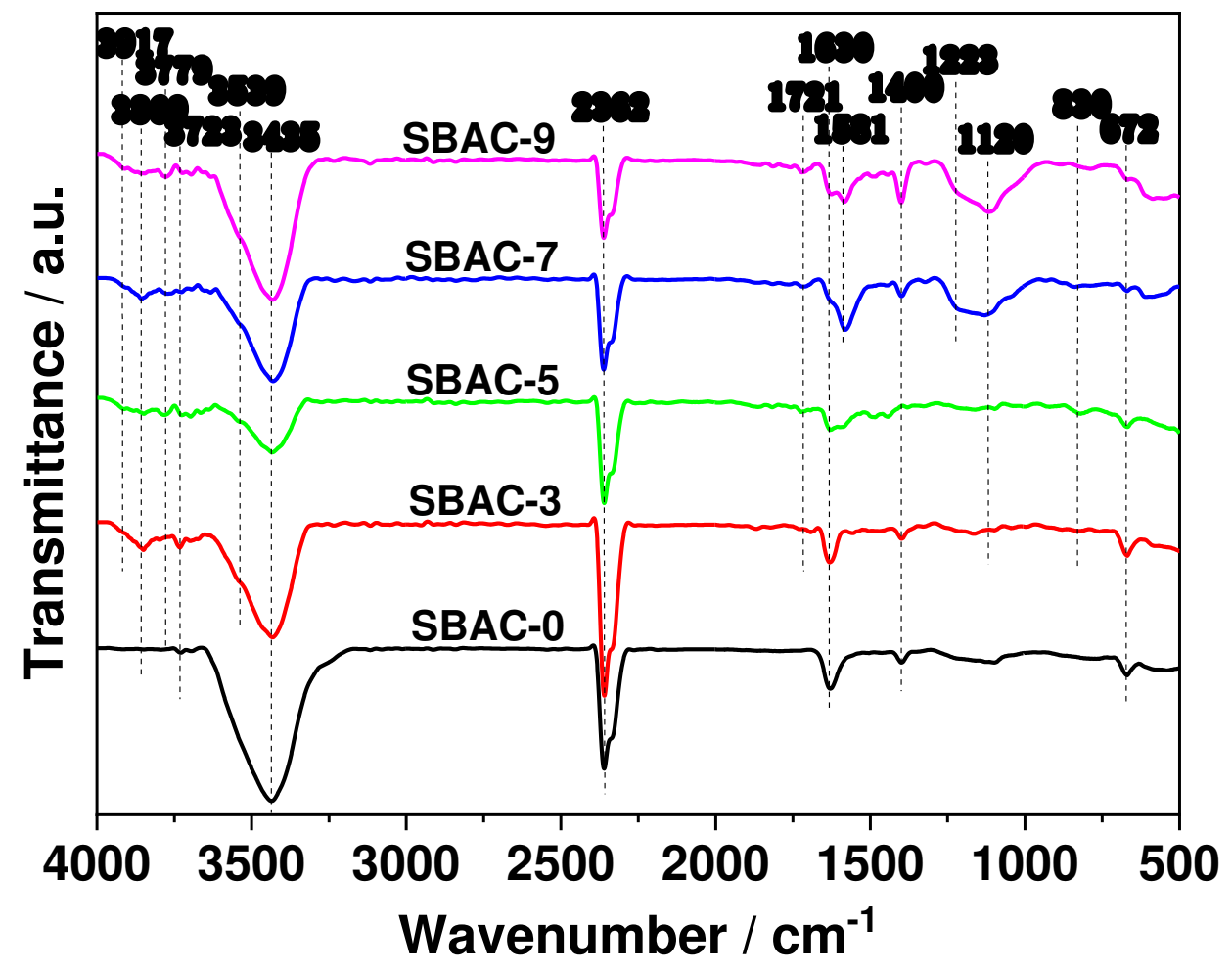


Figure 5
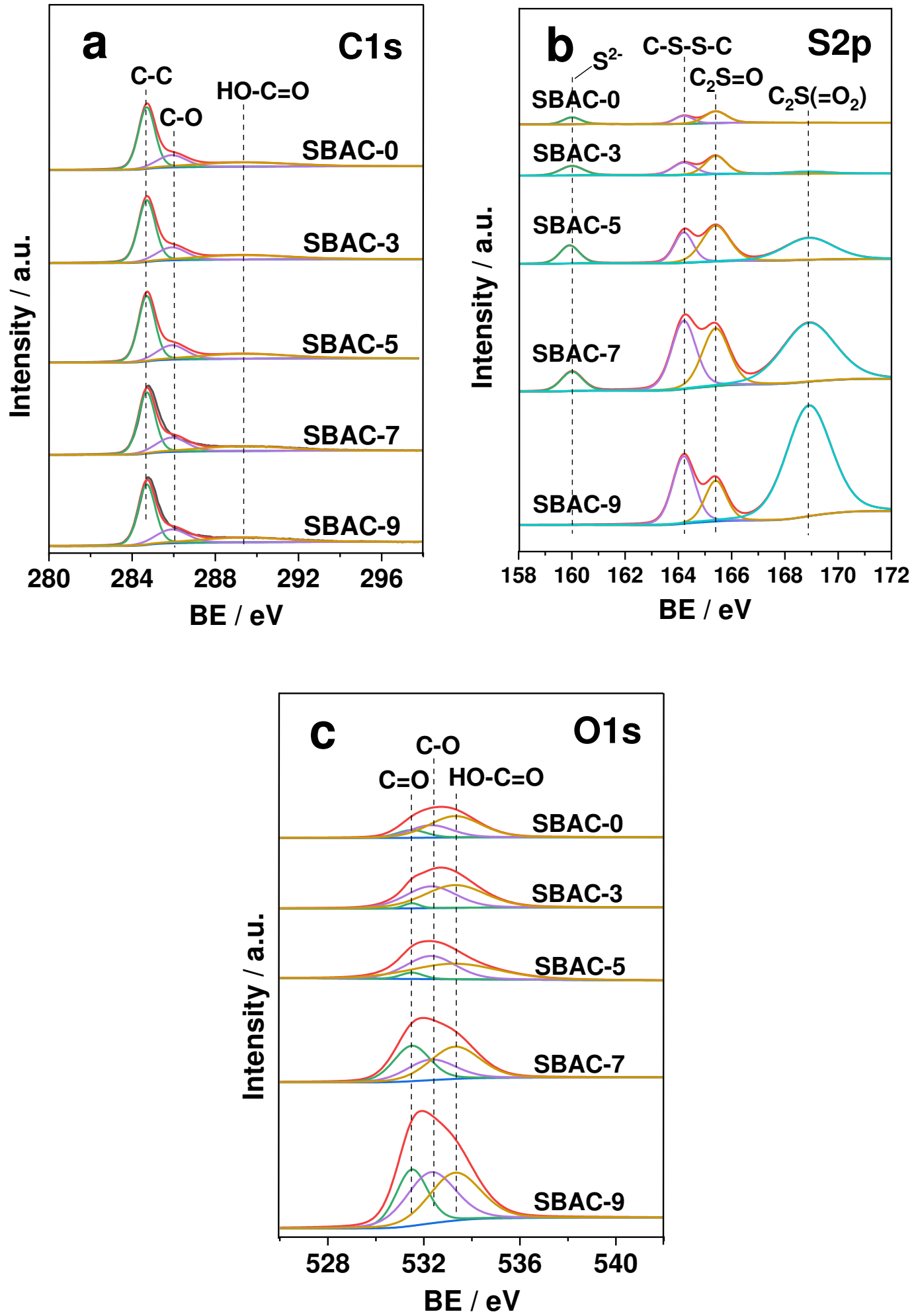
Figure 6

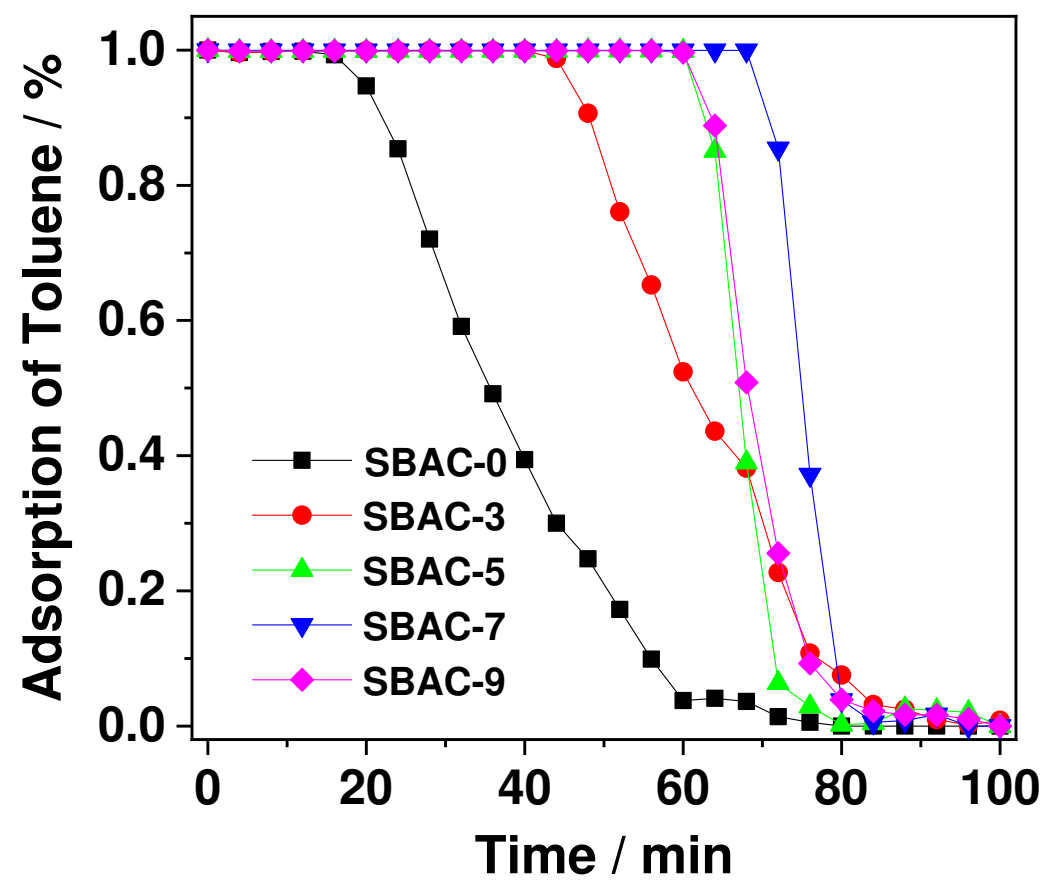


Figure 7

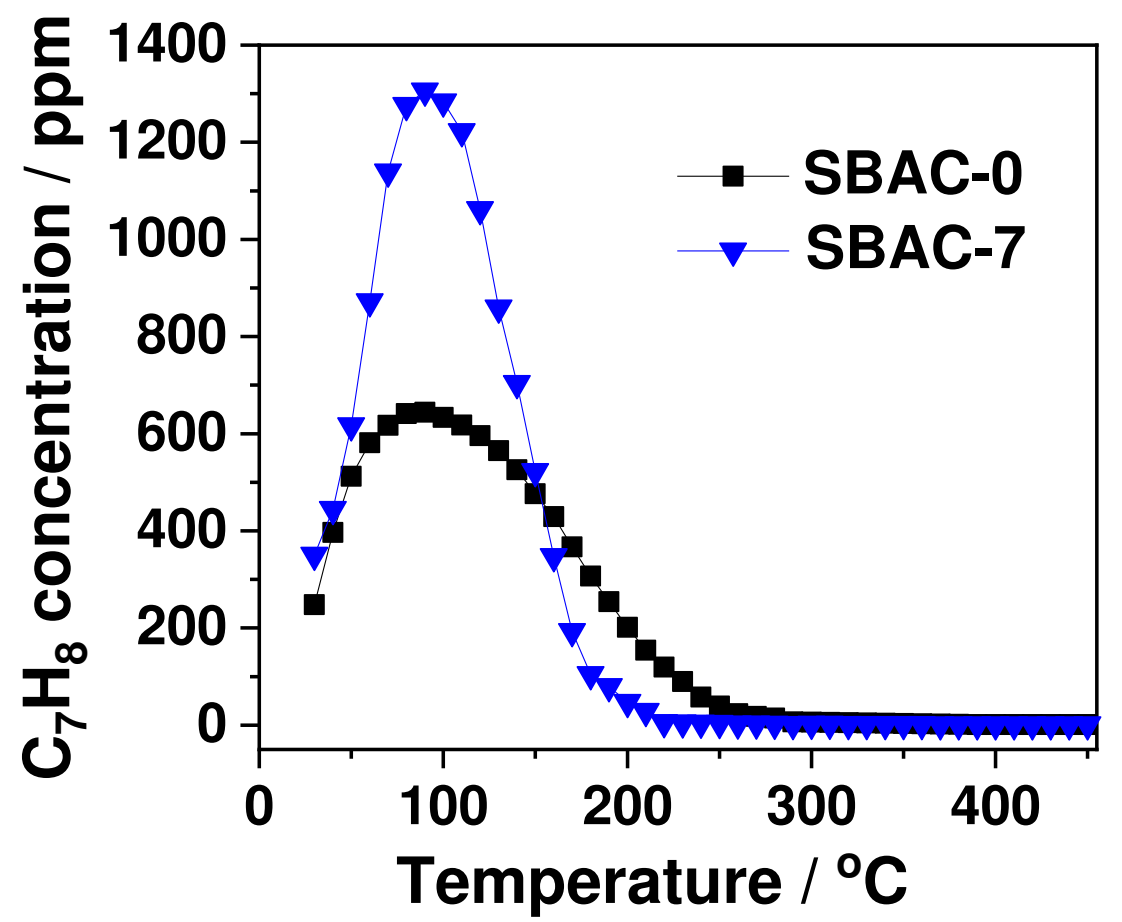


Figure 8

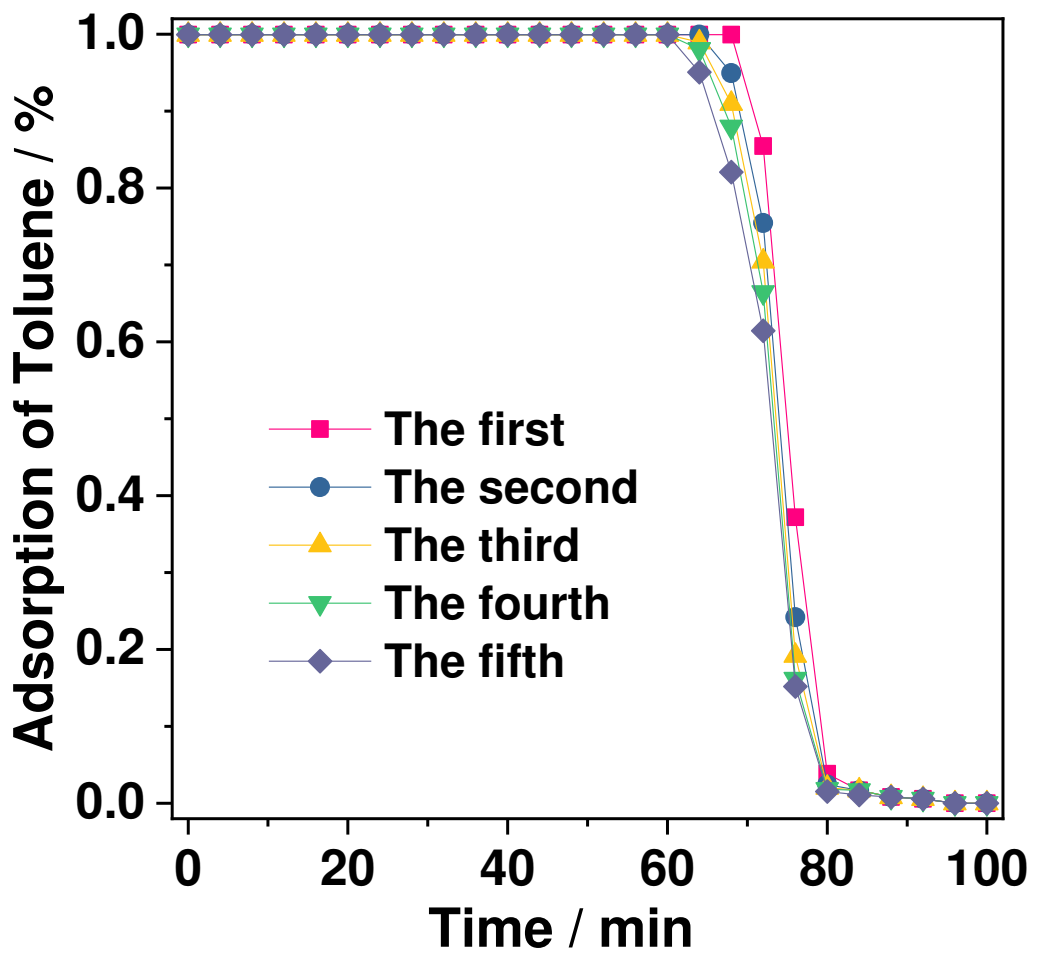


Figure 9
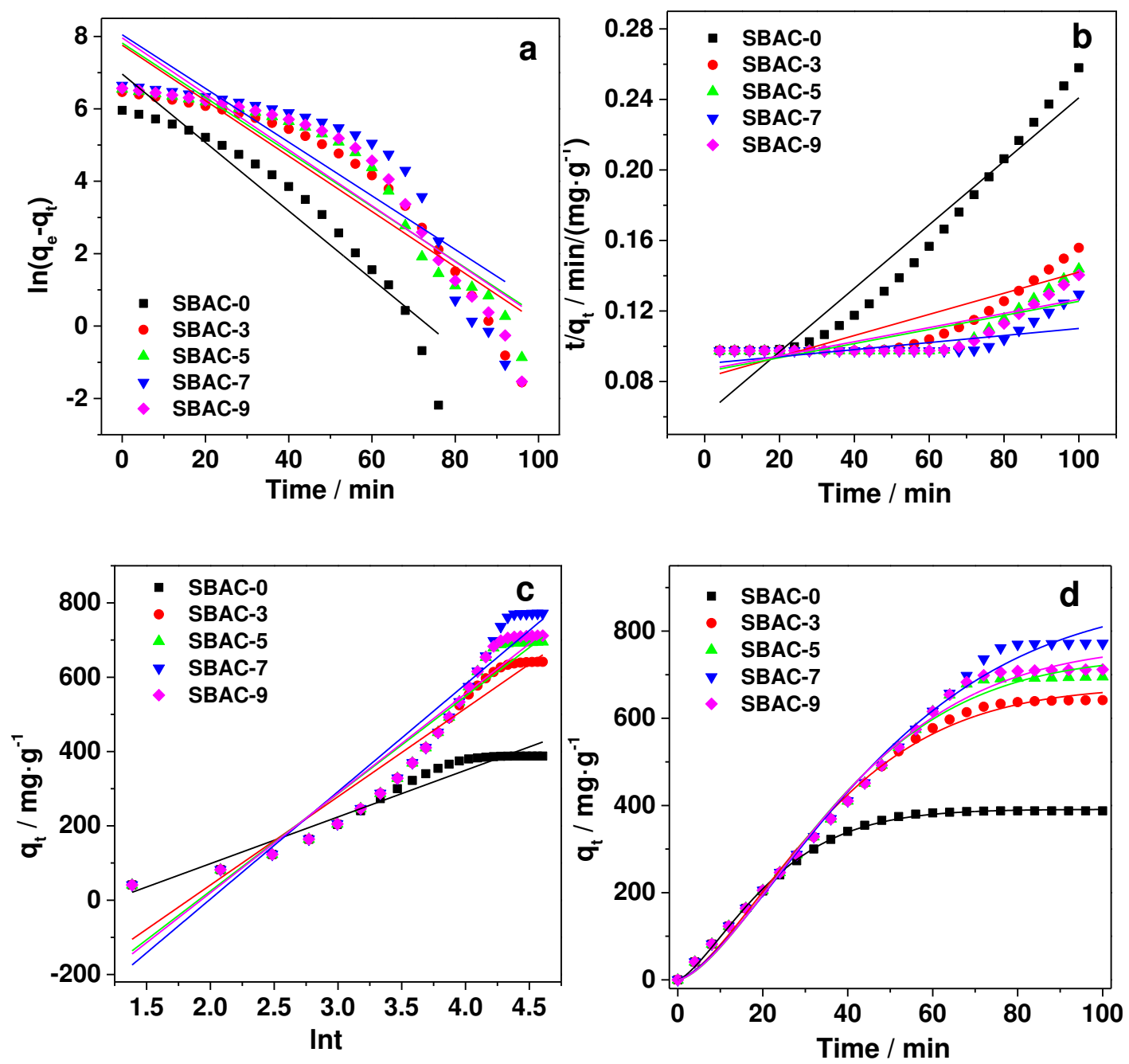
Figures

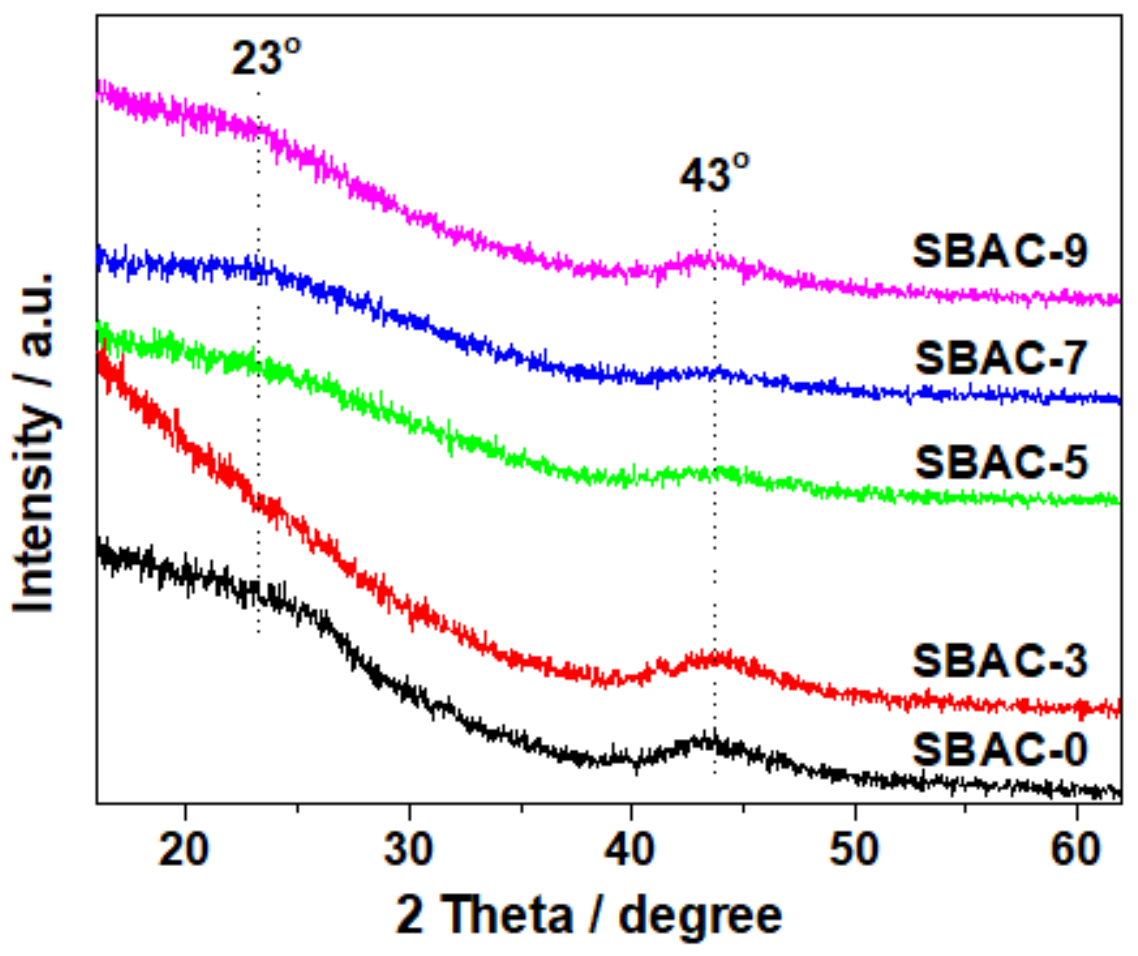

Figure 1

XRD patterns of the as-prepared samples. 

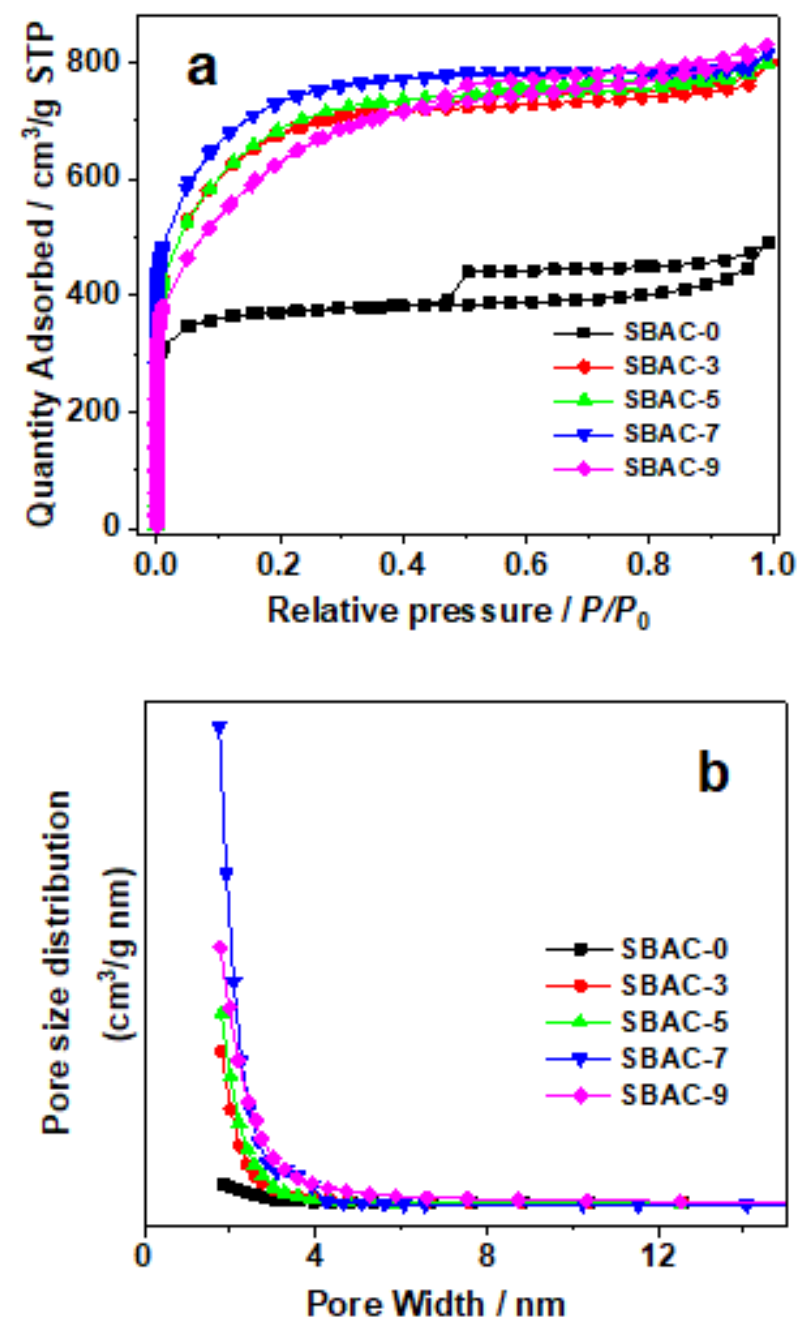

Figure 2

(a) N2 sorption isotherms and (b) pore-size distributions of the as-prepared samples. 


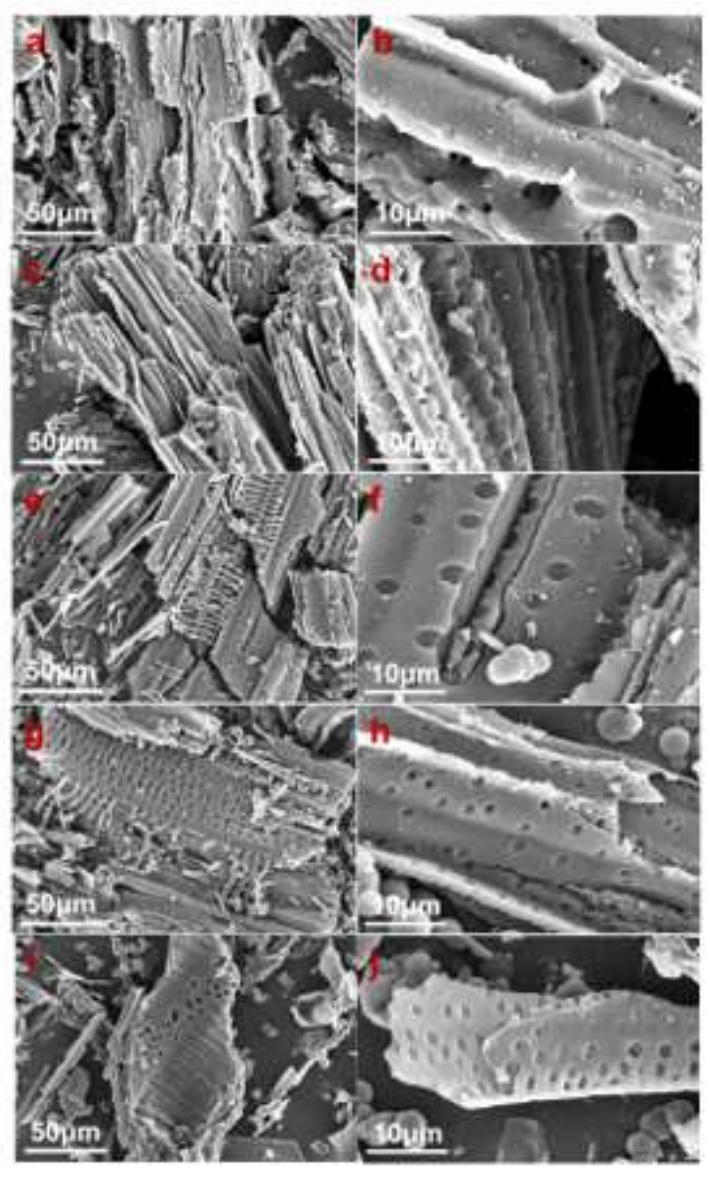

Figure 3

SEM images of as-prepared activated carbon samples SBAC-0 (a, b), SBAC-3 (c, d), SBAC-5 (e, f), SBAC-7 $(\mathrm{g}, \mathrm{h})$, and SBAC-9 $(\mathrm{i}, \mathrm{j})$. 


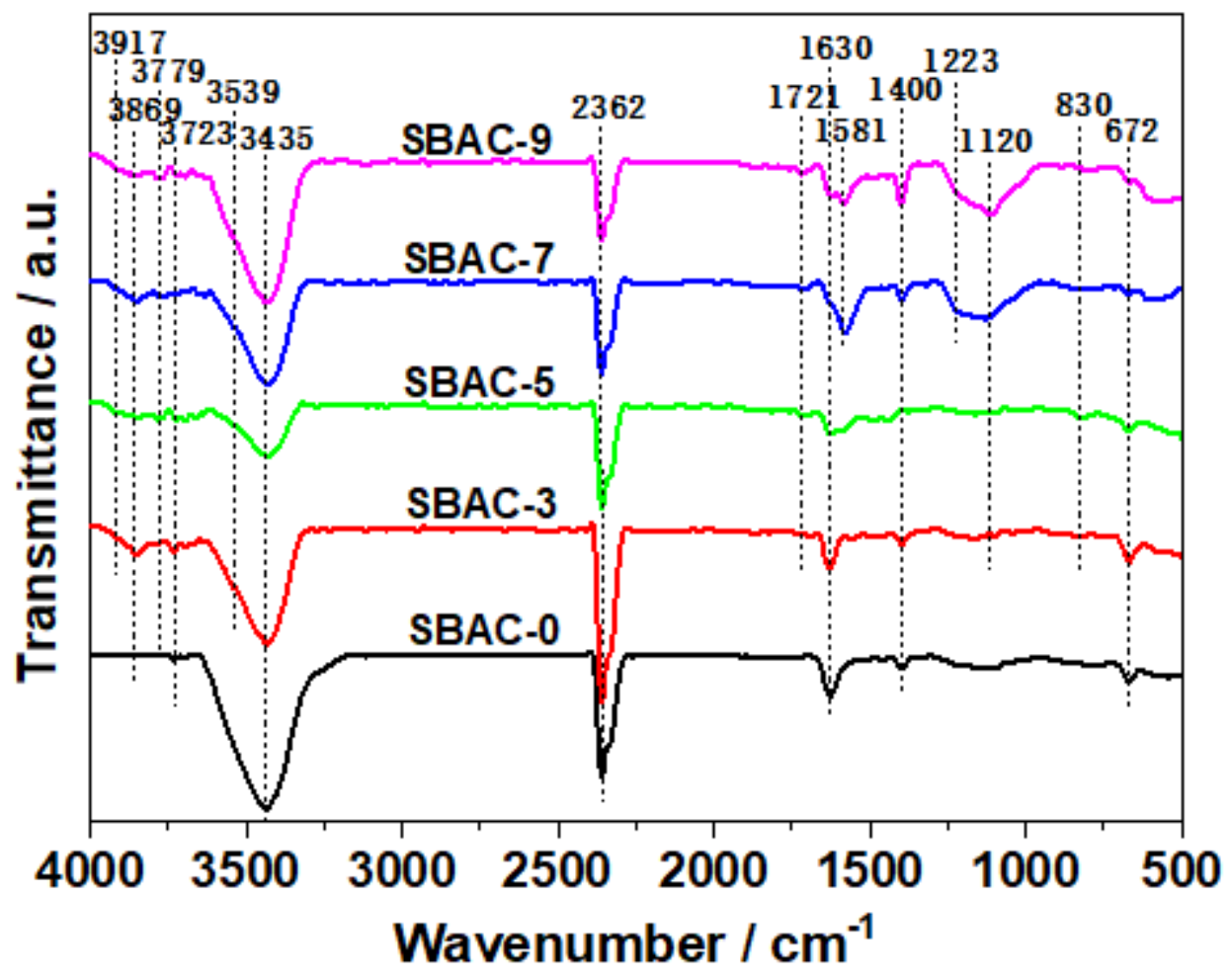

Figure 4

FT-IR spectra of the as-prepared samples. 

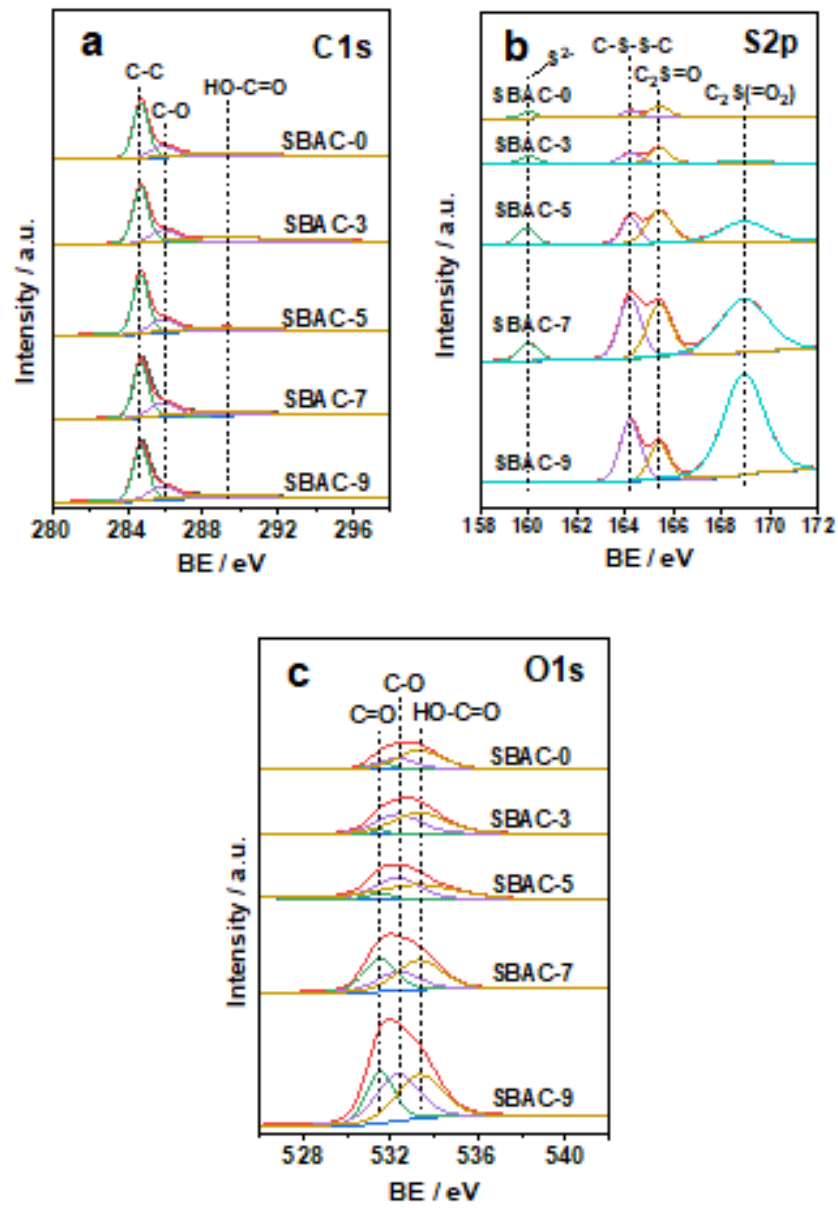

Figure 5

(a) C 1s, (b) S 2p and (c) 0 1s XPS spectra of the as-prepared samples.

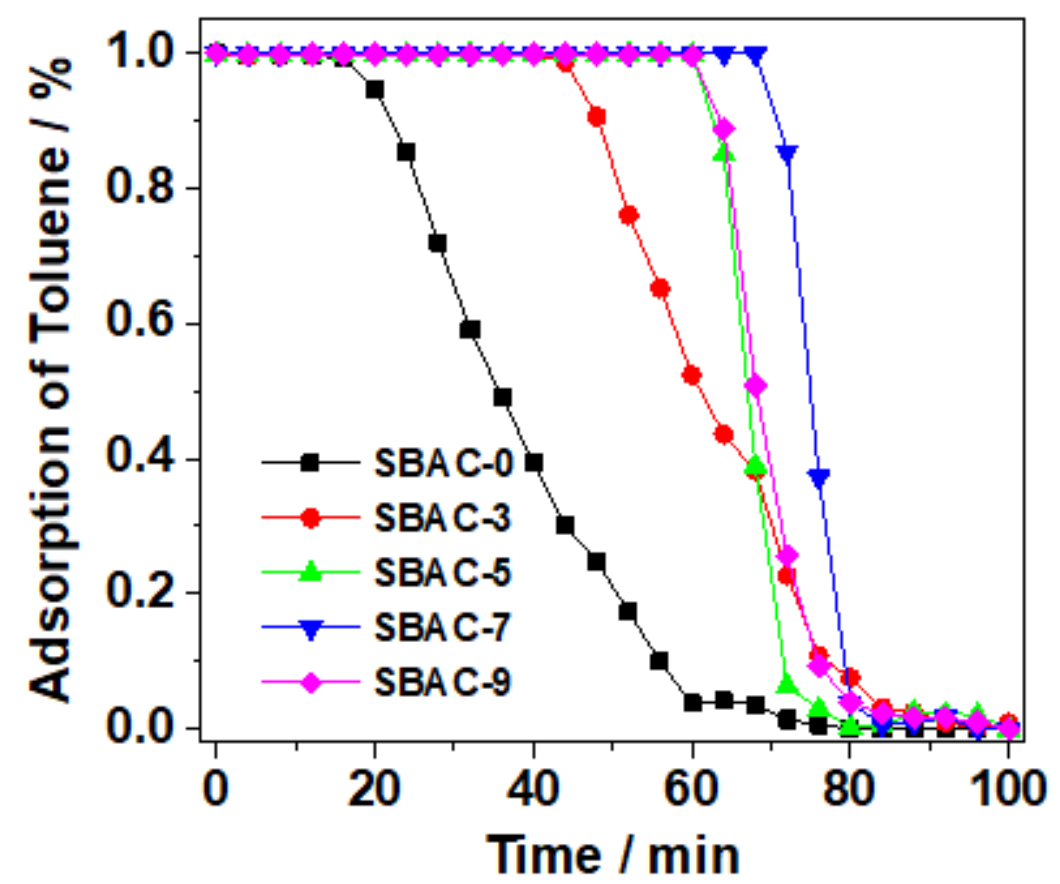


Figure 6

Adsorption breakthrough curves of as-prepared samples.

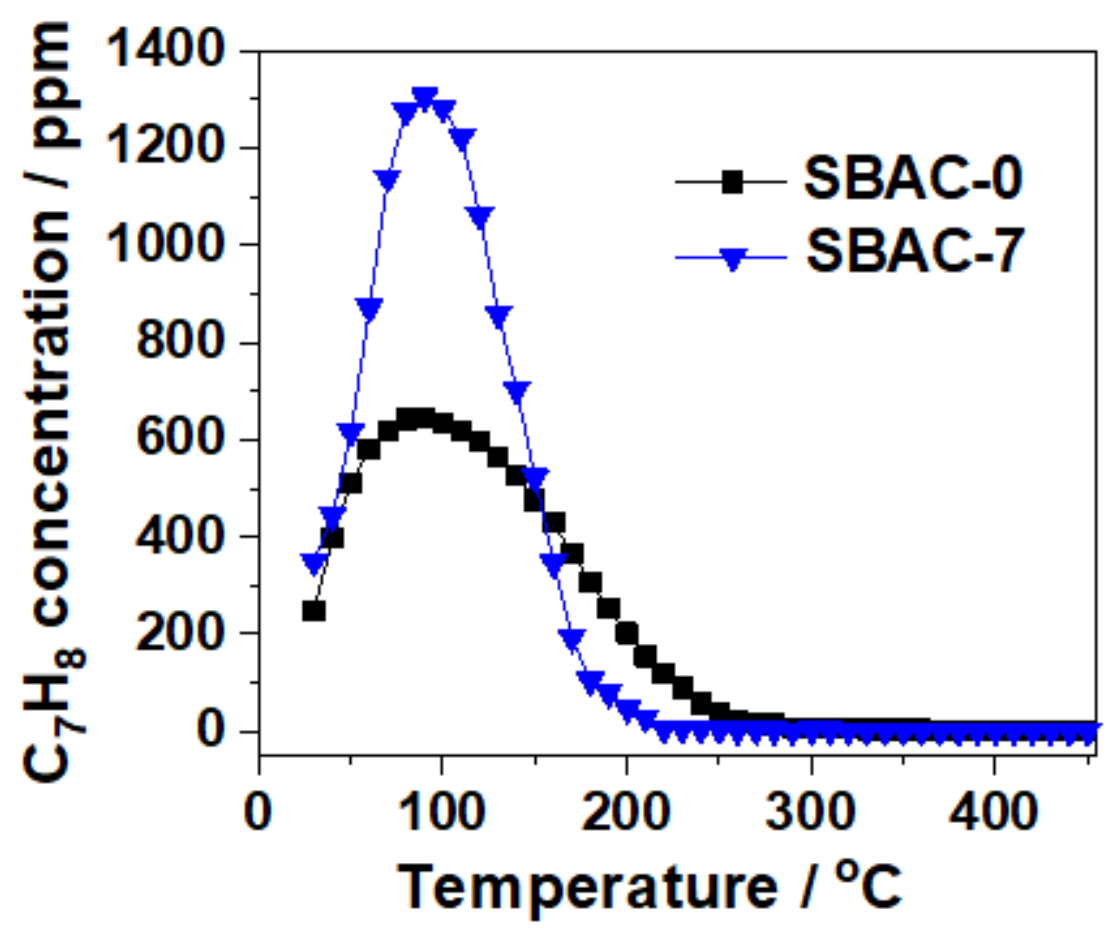

Figure 7

Desorption curves of SBAC-0 (a) and SBAC-7 (b). 


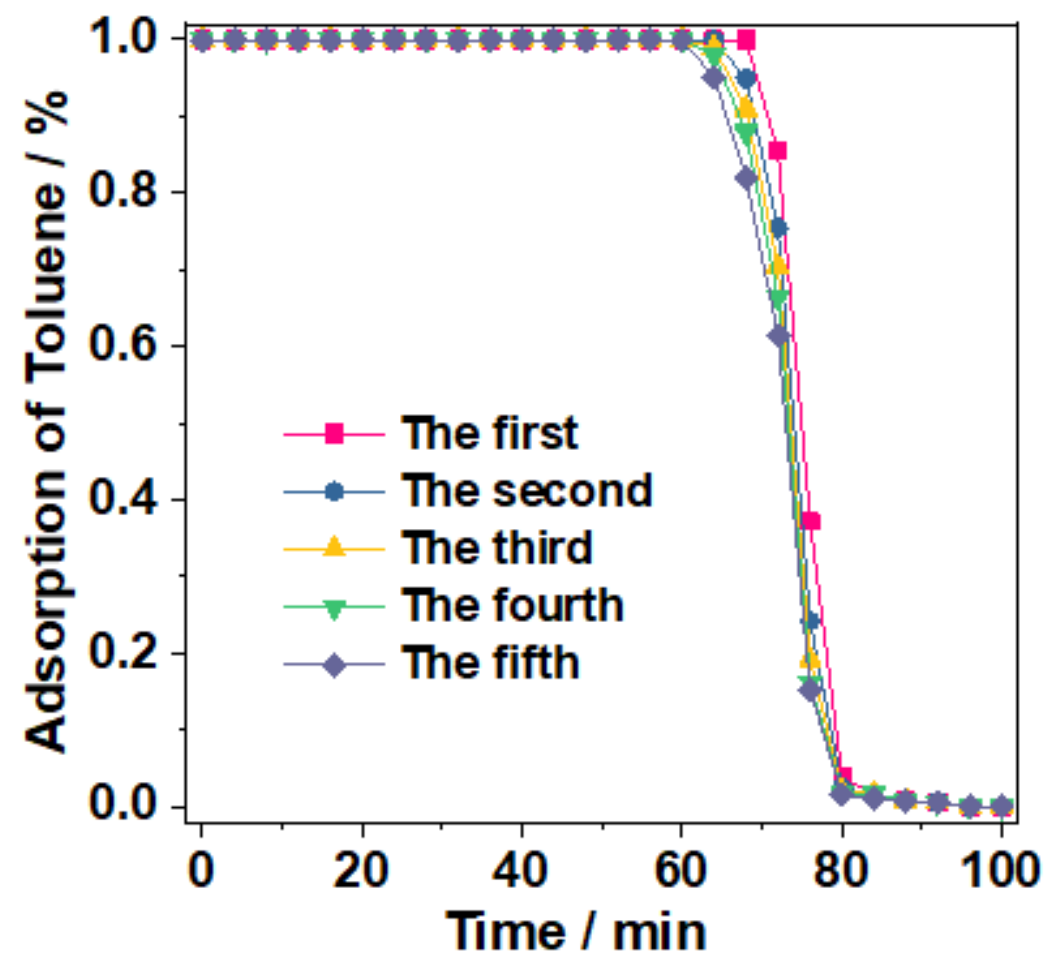

Figure 8

The consecutive toluene adsorption-desorption cycles of SBAC-7. 

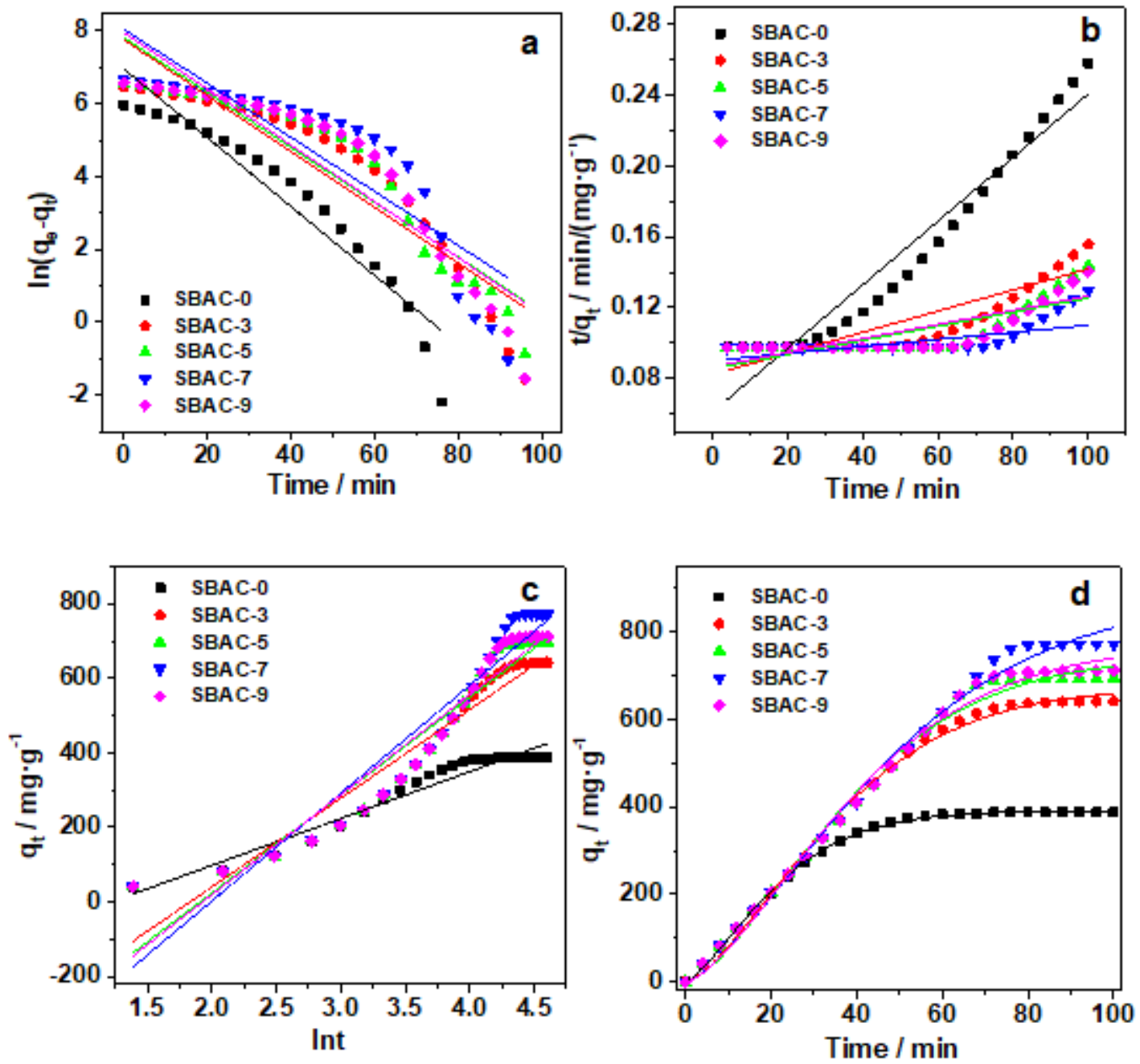

Figure 9

Adsorption kinetics model fit adsorption curve: (a) Pseudo-first-order model, (b) Pseudo-second-order model, (c) Elovich model, (d) Bangham model. 